2019-10-15

WHTO: A methodology of calculating

the energy extraction of wave energy

convertors based on wave height

reduction

Shi, $\mathrm{H}$

http://hdl.handle.net/10026.1/14828

10.1016/j.energy.2019.07.068

Energy

Elsevier

All content in PEARL is protected by copyright law. Author manuscripts are made available in accordance with publisher policies. Please cite only the published version using the details provided on the item record or document. In the absence of an open licence (e.g. Creative Commons), permissions for further reuse of content should be sought from the publisher or author. 


\section{WHTO: A methodology of calculating the energy extraction of wave energy convertors based on wave height reduction}

Hongda Shi ${ }^{\text {a, b }}$, Chenyu Zhao a ${ }^{\text {a }}$ Martyn Hann ${ }^{\mathrm{c}}$, Deborah Greaves ${ }^{\mathrm{c}}$, Zhi Han ${ }^{\mathrm{a}}$, Feifei Cao ${ }^{\mathrm{a} \cdot{ }^{*}}$

${ }^{a}$ College of Engineering, Ocean University of China, 238, Songling Road, Qingdao, 266100, China

${ }^{\mathrm{b}}$ Shandong Provincial Key Laboratory of Ocean Engineering, 238, Songling Road, Qingdao, 266100, China

${ }^{\mathrm{c}}$ COAST Engineering Research Group, School of Engineering ,Faculty of Science and Engineering, University of Plymouth, Reynolds Building, Drake Circus, Plymouth, Devon PL4 8AA 


\begin{abstract}
Wave energy has significant worldwide exploitable resource and its exploitation has attracted renewable energy investigator' attention. Great progress on calculating device performance has been made by means of theoretical, numerical and model tests. This paper presents a method of calculating the energy extraction of a wave energy converter (WEC) based on Wave Height Takeoff (WHTO). The method provides a means to improve the capture efficiency of designs, including demonstrating how well different kinds of WEC are optimized for certain wave conditions. Numerical simulations of a heaving buoy and a bottom-hinged pendulum in a 2D wave flume with different damping types (linear and nonlinear) are presented. The results show that the difference between the calculated energy extraction from the wave height reduction and from the model power take-off (PTO) was not significant in a 2D flume. Physical model tests were conducted using a simplified PTO consisting of a system of lifting weights, used to measure the energy extraction directly. Based on both numerical and physical model analyses, the article defines WHTO, which is equivalent to energy extracted by PTO, but determined without taking direct measurements. This paper aims to promote and validate the concept of the WHTO.
\end{abstract}

Keywords: wave energy, Wave Height Take-off, numerical simulation, model test 


\section{Introduction}

Wave energy has aroused great interest due to the significant exploitable resource. The majority of wave energy converters (WECs) which convert wave energy into electricity can be summarized in three different types: oscillating water column (OWC), overtopping devices (OTDs), and wave activated bodies (WABs[1][2]. The energy conversion of the WECs can generally be divided into two steps: energy extraction from the wave oscillations; and the conversion of this extracted energy to electrical energy by a power take-off (PTO) system[3]. The majority of PTO that have been studied as: pneumatic (such as OWCs), hydraulic (WABs) or direct electricity generation (WABs)[4].

In recent decades, efforts have been made to find and enhance the extracted power from WECs by optimizing geometrical characteristics, PTO forms, and control strategies with analytical, numerical and physical methods. For instance, Shi et al proposed a formula based on Morison equation to seek the maximum extractions of a hydraulic system, which is applied in a heaving buoy WEC [5]. Zheng et al evaluated the maximum power absorption of the two interconnected floaters by a mathematical model based on the three-dimensional wave radiation-diffraction theory [6]. Lewis et al discussed the maximum energy extraction of WABs in time and frequency domain by optimizing the PTO damping [7]. Renzi et al applied a mathematical model to investigate the influence of the channel sloshing modes on the performance of a pendulum device[8]. Zhang $\mathrm{X}$ et al first applied a nonlinear PTO system to an oscillating-body WEC by using two symmetrically oblique springs to make the system bi-stable; The results showed that bi-stable PTOs can dramatically improve power capture performance compared to linear PTOs with relatively lowfrequency waves [9].

When energy is extracted by a WEC, a reduction in wave height is expected. Previous studies have examined the change in the wave field surrounding a WEC by physical and numerical methods: Zanuttigh et al Error! Reference source not found. studied a floating WEC (DEXA - a raft WEC with two floating bodies) acting as a floating breakwater using model tests, comparing the difference of protection ability between the DEXA and a traditional floating breakwater. Two physical models (the larger one with a PTO and the smaller without) with different scale ratio were tested. The results 
showed that wave transmission and the energy absorption efficiency were strongly related to the ratio of device length to the wave length. When the ratio increased, the wave transmission trends to decrease, while absorption efficiency increased until the peak (ratio $=1)$ then it also decreased. Wave reflection had the opposite trend to the transmission due to energy conservation. The differences between the two scale models showed that the PTO decreased the wave transmission. Beels et al [11] used a time-dependent mild-slope equations 3D numerical model to analyse the wake effect behind an overtopping WEC called Wave Dragon, finding the irregular long-crested wave cases experienced a large decrease of wave energy while the short-crested cases have a faster wave redistribution. Later, Nørgaard et al [12] conducted an experiment focusing on the transmitted wave energy behind the Wave Dragon, discussing the wake effects including the transmission wave height reduction in a 3D basin by a numerical model after validating based on the experimental results. In this test, it was also found that the mooring type affected the wave transmission. Stratigak et al [13] tested the wave transmission of a point absorber in both a 2D flume and 3D basin. The device used in the experiment had a mechanical PTO system consisting of a brake providing constant damping. To limit 3D affects, the device width was made equal to the flume width in the 2D case. The tests were intended to optimize the extraction of the PTO and validate the numerical models.

Wave reduction is also significant within wave farms. Palha et al [14] used a REFDIF model to calculate the device absorption in five different wave farms configurations of the Pelamis WEC. It was found that the wave height variation may be significant due to the energy extraction of the WEC in several situations, while the direction variation was quite low. Stratigak et al [15]conducted an experiment in a large basin with an array of heaving buoys under different wave conditions including regular and irregular wave conditions. A significant wave height reduction in the downwave areas was reported, which nearly reached $20 \%$ while the reduction was dependent on the wave conditions. Haller et al [16]used three arrays (single device, three devices and five devices) to find how the effect on the wave field was influenced by the number of devices. For a single device, the relative capture width decreased with an increasing wave period and the wave height reduction was not significant in the far-field. In the multi-devices cases the wave height reduction increased when more devices were added into the array and it was still significant in the far-field. 
A 2D flume is employed, the energy loss of the wave is equal to the sum of the device's absorption and any propagation losses. This paper demonstrates the measurements of the wave height reduction can be used to calculate the energy extracted by a WEC. The concept of Wave Height Take-off (WHTO) is proposed as a measure of energy absorption. The remainder of the paper is organized as follows: Section 2 designs a 2D numerical wave flume and defines WHTO. Section 3 presents numerical simulation results demonstrating the WHTO concept. Section 4 discusses model tests of a heaving buoy and a bottom hinged pendulum WEC, which demonstrates the feasibility of the method. Conclusions are drawn in Section 5.

\section{Concept of WHTO}

In liner theory, the energy carried by a regular wave in one wavelength can be presented as:

$E_{w}=\frac{1}{8} \rho g L D H^{2}$

where the $\rho$ is water density, $g$ is acceleration of gravity, $H$ is wave height, $L$ is wavelength, $D$ is the wave crest line width.

In the same wave period, the unit width energy is proportional to the square of the wave height. The wave height which is relevant to the PTO is defined as WHTO. So, there is an assumption (shown in (2) that the device's energy is proportional to the square of WHTO,

The energy extracted by the device can be represented as:

$E_{P T O}=C_{P T O}^{2}$

where the $C$ is a parameter which is related to wave condition, $H_{P T O}$ is the WHTO.

When the capture width of the device is nearly the same as the flume wide, the waves focusing effects can be ignored in the 2D flume.

Considering the energy conservation:

When the device is absent in the flume:

$\frac{1}{8} \rho g L D N H_{0}^{2}=\frac{1}{8} \rho g L D N H_{T}^{2}$

where the $H_{0}$ is the incident wave height, $H_{T}$ is the transmitted wave height, $N$ is the number of 
wave in a case time.

When the device is in the flume but fixed or operates with no damping which means there is no energy absorption,

$\frac{1}{8} \rho g L D N H_{0}^{2}=\frac{1}{8} \rho g L D N H_{r}^{2}+\frac{1}{8} \rho g L D N H_{T}^{2}$

where $H_{r}$ is the reflect wave height. When the device is in the flume and operates with PTO,

$\frac{1}{8} \rho g L D N H_{0}^{2}=\frac{1}{8} \rho g L D N H_{r}^{2}+\frac{1}{8} \rho g L D N H_{T}^{2}+C H_{P T O}^{2}$

If it is assumed that the reflection and transmission have the same wave period as the incident wave

then $\quad C=\frac{1}{8} \rho g L D N$ can be substituted into (5)

$H_{0}^{2}=H_{r}^{2}+H_{T}^{2}+H_{P T O}^{2}$

The PTO is in the form of a mass being lifted via a gearbox arrangement, which applies a constant damping value. This PTO can be modelled as:

$E_{\text {PTO }}=M g h$

where the $M$ is the mass of the weight, and the $h$ is the lifting displacement.

According to the (2) (6) and (7):

The $C$ can be presented as:

$C=\frac{M g h}{H_{0}^{2}-H_{r}^{2}-H_{T}^{2}}$

In the following part, the assumption of $C$ will be verified and the maximum power extraction of different devices under certain waves calculated by the above mothed.

\section{Numerical simulation}

The type of PTO damping applied to a WEC is difficult to change in physical model tests, but is convenient to alter in simulations. Here, numerical simulations are used to investigate the influence of the PTO damping type. The simulations in this paper are conducted by Flow-3D[17], a computational fluid dynamic (CFD) software, applying the finite difference method[18] to solve the RANS equations [19] which are written in terms of Cartesian coordinates. The RNG k- $\varepsilon$ turbulence model was applied due to regular waves being modelled. The WECs were modelled by a general moving object (GMO) model. All equations are formulated with area and volume porosity functions. 
This formulation, called FAVOR ${ }^{\mathrm{TM}}$ for Fractional Area/Volume Obstacle Representation Method is used to model complex geometric regions. In Flow-3d, the core of the GMO is the FAVOR method, applied to describe and calculate the motion of the device in each degree.

To find the most suitable PTO type, a numerical wave tank (NWT) was used to simulate the device motion with different damping types. As shown by Fig.1, the NWT was $50 \mathrm{~m}$ long, $0.7 \mathrm{~m}$ wide and $2 \mathrm{~m}$ high (the water depth is $1 \mathrm{~m}$ ), divided into two zones (Zone 1 and Zone 2). Each zone consists of cubic cells. The WEC model is in Zone 1, which has a finer mesh than Zone 2. The boundaries of the two zones can been seen in Table 1. Simulations were conducted for both a heaving buoy and pendulum device. The results of a mesh resolution study for both cases can be seen in the Fig.2. The ratio between the flume width and the cell length is defined as $r_{0}$. In the heaving buoy case, buoy velocity is different in $r_{0}=2.33$ cell and $r_{0}=2$ cell, meaning the cell size still influenced the results. When $r_{0}>3.5$, the results are independent of the cell size. The computing time length in $r_{0}=7$ case is not much longer than in the $r_{0}=3.5$ case ( 3 min $21 \mathrm{~s}$ and $3 \min 50 \mathrm{~s}$, respectively). So, in the heaving buoy cases a cell size of $r_{0}=7$ was used. The length of the pendulum device along the incident wave direction was smaller than the buoy (heaving buoy: $0.5 \mathrm{~m}$ and pendulum: $0.15 \mathrm{~m}$ ) and the generated motions were smaller. Hence a smaller and finer mesh was needed for the pendulum compared to the buoy. The modelled pendulum velocity was the same when the cell sizes were $r_{0}=15.5$ and $r_{0}=14$, with $r_{0}=14$ being selected for zone1.

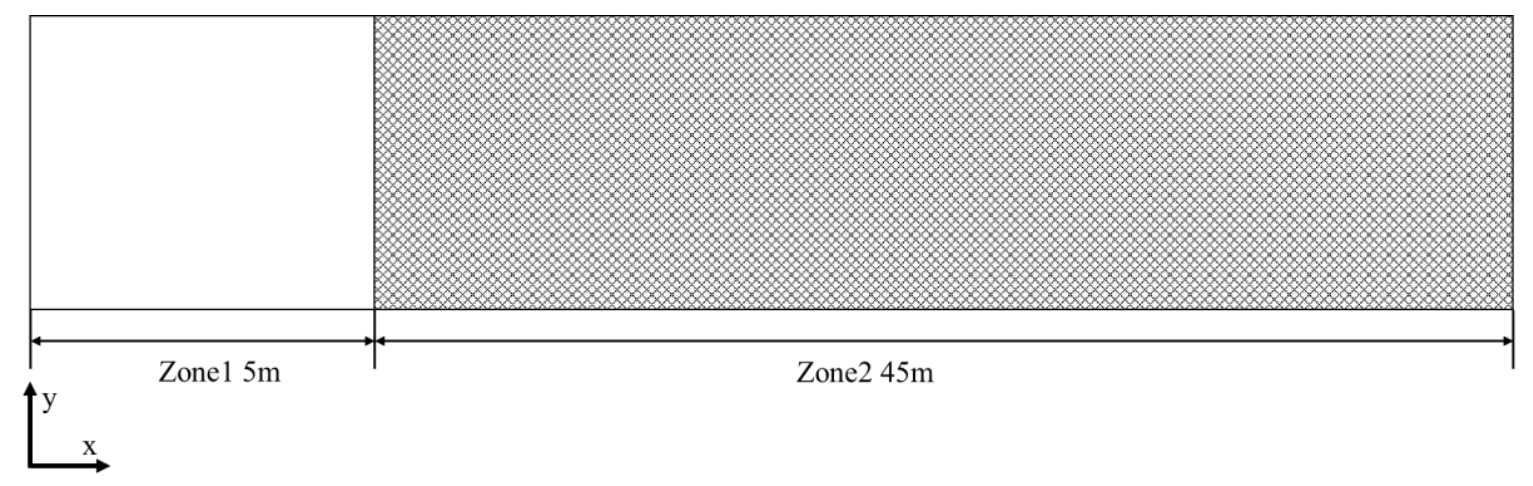

Fig.1 Side view of the NWT. The WEC located in Zone 1. Zone 2 is used for wave absorption. 
Table 1 Boundary conditions of NWT

\begin{tabular}{ccc}
\hline & Zone 1 & Zone 2 \\
\hline$X_{\min }$ & Linear wave & Symmetry \\
$X_{\max }$ & Symmetry & Outflow with wave absorber \\
$Y_{\min }$ & Symmetry & Symmetry \\
$Y_{\min }$ & Symmetry & Symmetry \\
$Z_{\min }$ & Wall & Wall \\
$Z_{\max }$ & Specified pressure & Specified pressure \\
\hline
\end{tabular}

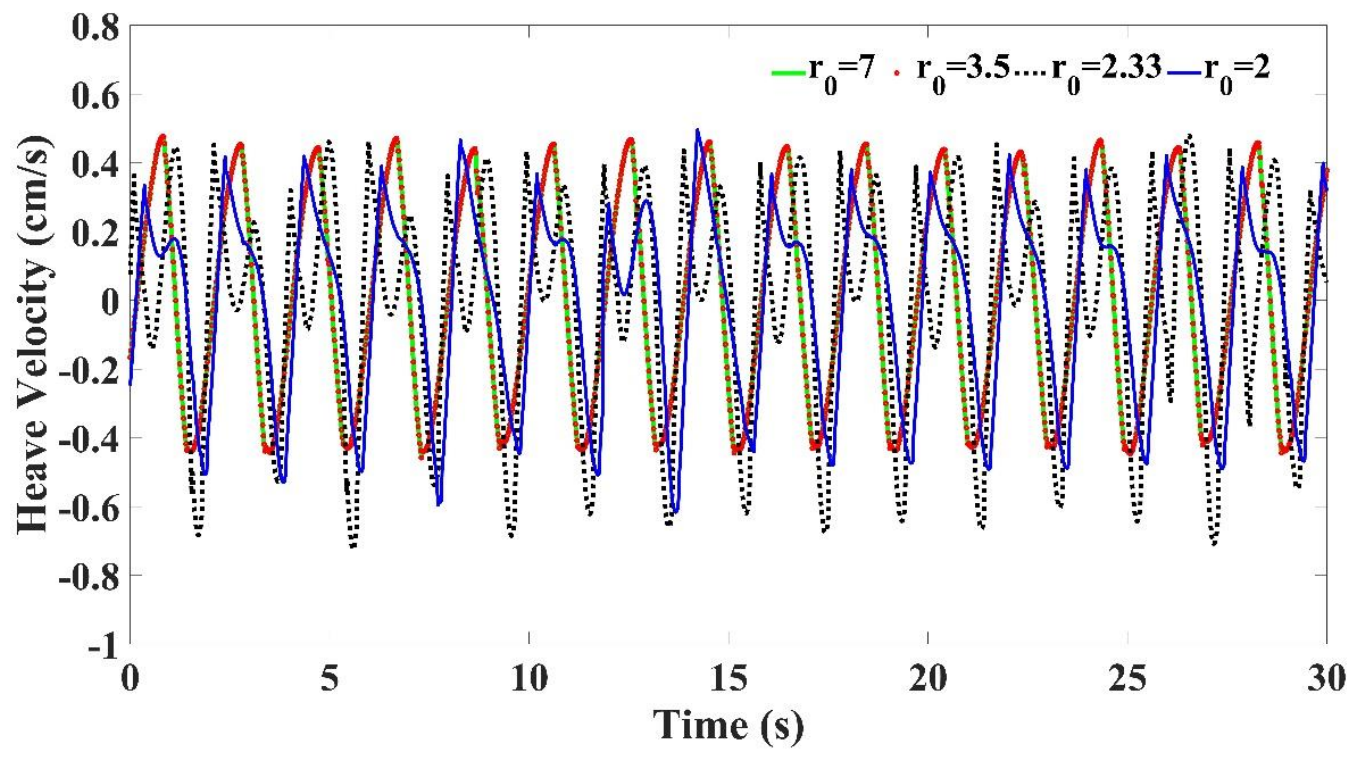

(a) 


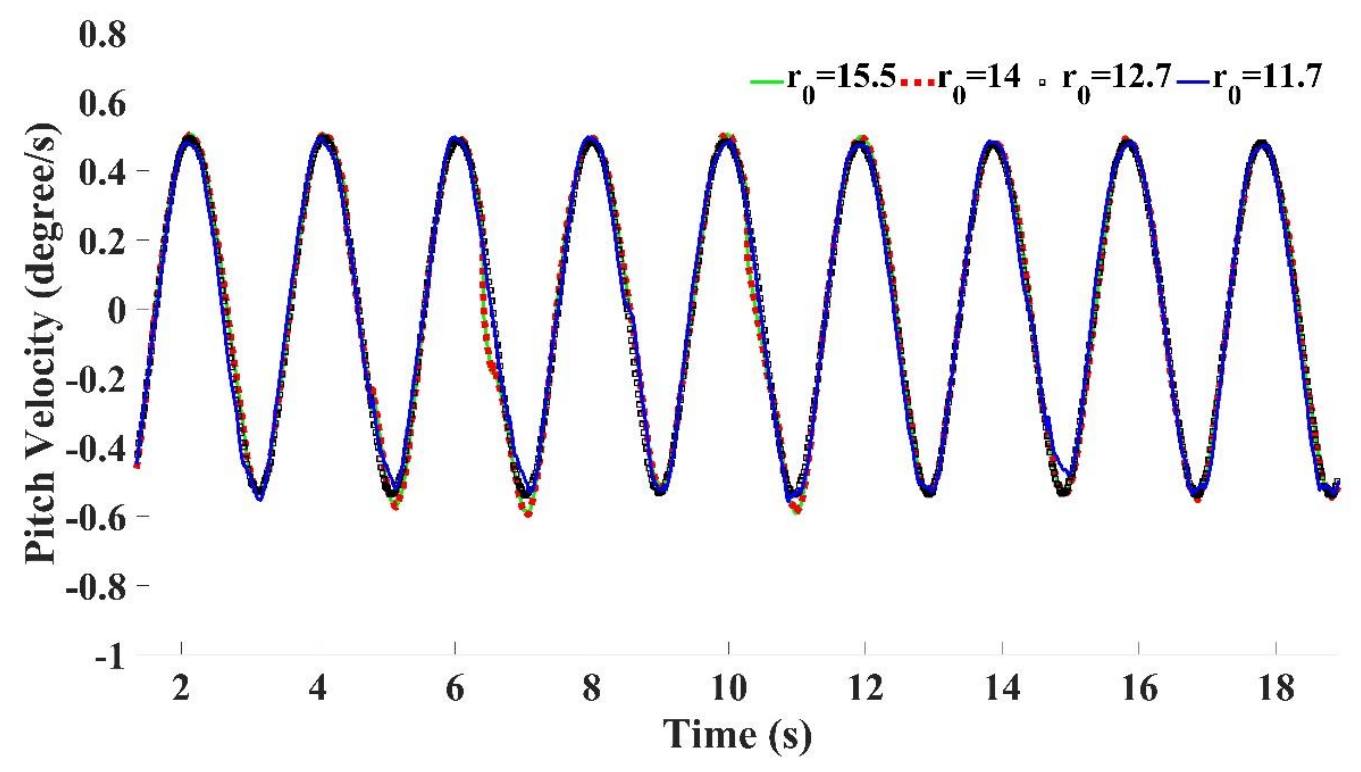

(b)

Fig.2 Results of mesh resolution study for (a) heaving buoy and (b) pendulum device, with different cell size. $H=0.2 m, T=1.9 \mathrm{~s}$

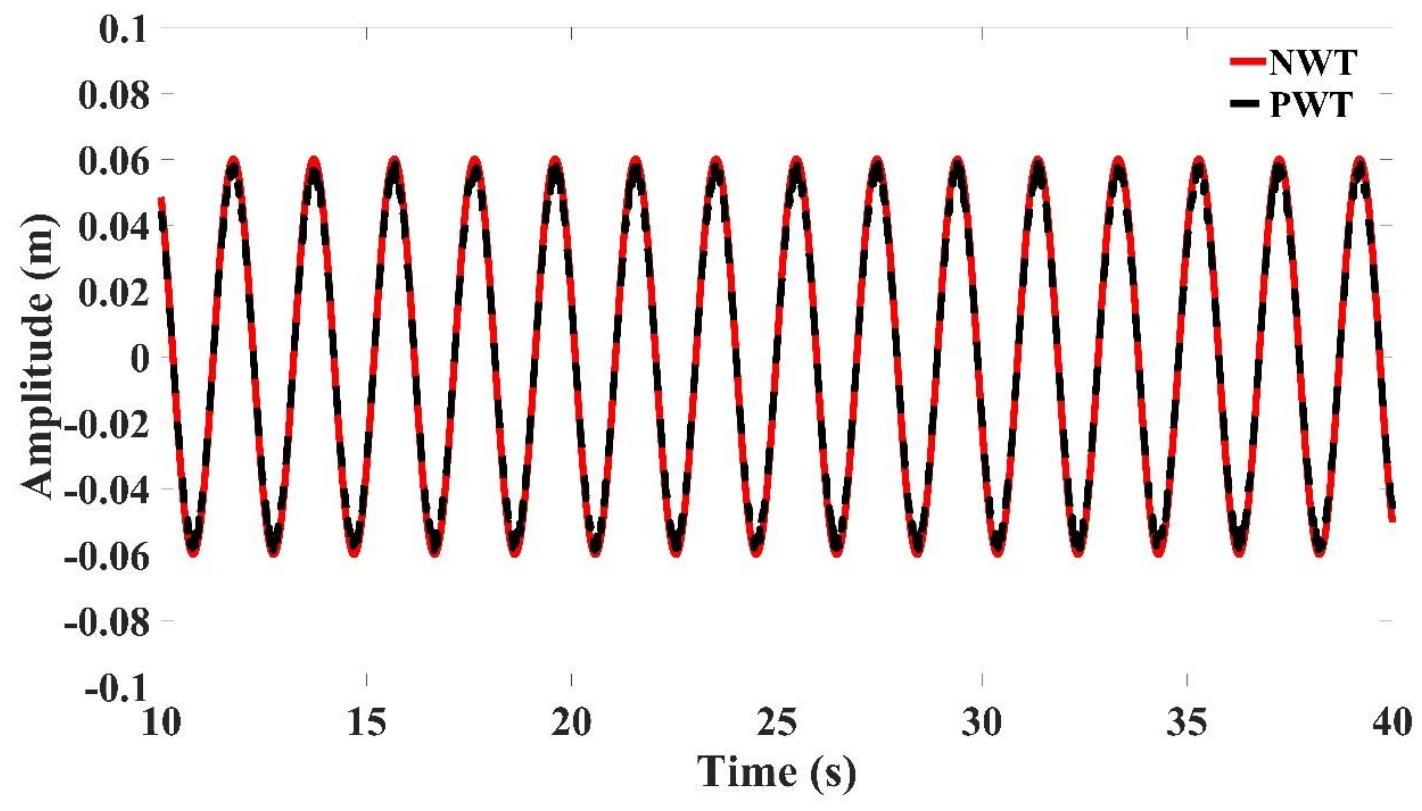

(a) 


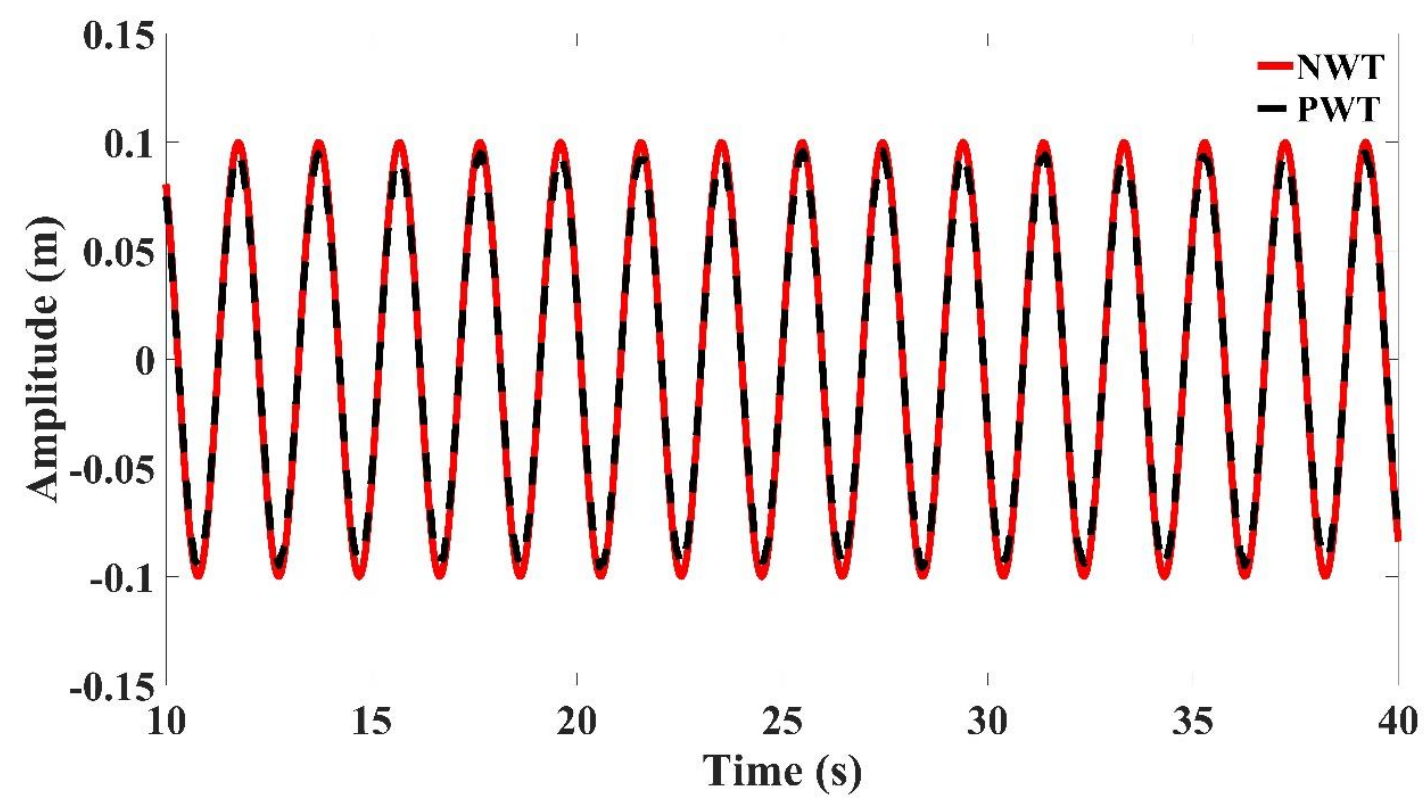

(b)

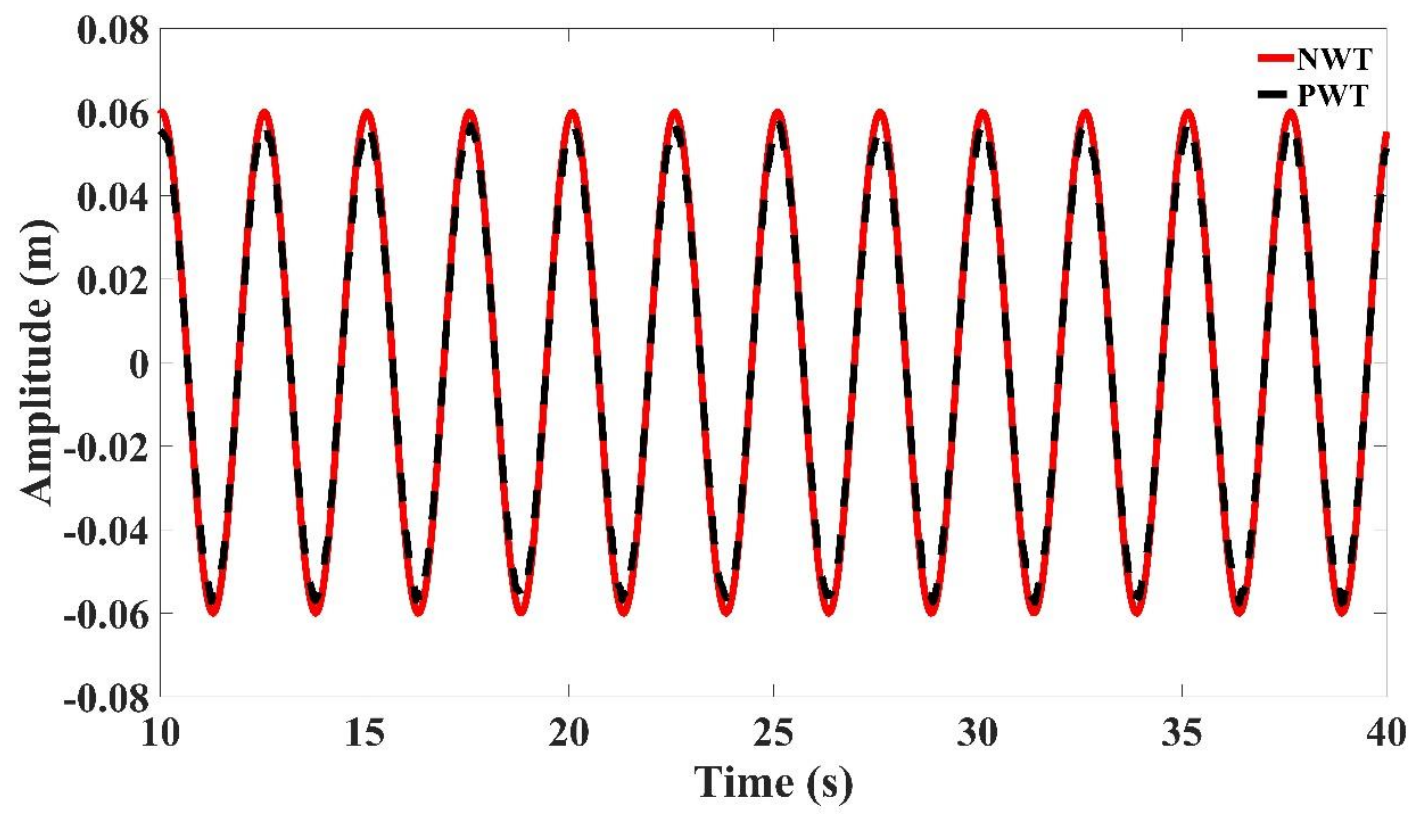

(c)

Fig.3 The validation of NWT, comparing physical model measurements and numerical model predictions of surface elevation with regular waves of (a) $T=1.96 \mathrm{~s} \mathrm{H}=12 \mathrm{~cm}$ (b) $T=$ $1.96 \mathrm{~s} H=20 \mathrm{~cm}$ (c) $T=2.51 \mathrm{~s} H=12 \mathrm{~cm}$

The function of the Zone 2 is to absorb the wave, reducing the reflection. Porous wave absorbing is applied at the end of NWT with a 0.7 coefficient. The other parameters can be seen in Table 2. The NWT has been validated by the physical wave tank (PWT) which is used in the model test. The results can be seen in the Fig.3, amplitude of NWT waves are larger than in PWT, believed to be due to the losses from the tank bottom in the PWT.

Table 2 Numerical parameter used during simulations of Heaving Buoy and Pendulum WEC 


\begin{tabular}{|c|c|c|}
\hline Input conditions & Heaving buoy (Cuboid) & Pendulum \\
\hline$T: 1.96 \mathrm{~s}, 2.51 \mathrm{~s}$ & Size: $500 * 700 * 500 \mathrm{~mm}$ & Size: $150 * 700 * 700 \mathrm{~mm}$ \\
\hline \multicolumn{3}{|l|}{$H: 0.2 \mathrm{~m}, 0.12 \mathrm{~m}$} \\
\hline Deep: $1 \mathrm{~m}$ & Density: $600 \mathrm{Kg} / \mathrm{m}^{3}$ & Density: $335 \mathrm{Kg} / \mathrm{m}^{3}$ \\
\hline $\begin{array}{l}\text { Wave tank length and width: } \\
50 \mathrm{~m} \text { and } 0.7 \mathrm{~m}\end{array}$ & $\begin{array}{l}\text { Damping type: a. constant } K \\
\text { b. liner type } K V\end{array}$ & $\begin{array}{l}\text { Damping type: a. constant } K \\
\text { b. liner type } K \omega_{p}\end{array}$ \\
\hline
\end{tabular}

As shown by Table 2 the width of the two devices is the same as the tank width. The density of these two devices is also the same as applied in the model test. The energy capture calculated by the WHTO technique and directly from the modelled motions is compared for two different PTO damping types applied to the heaving buoy device (Fig. 4) and pendulum device (Fig. 5). A constant damping and a linear damping (proportion to velocity or angle velocity of the device) are used in the simulation. The energy absorbed by PTO in the heavying buoy device is calculated by $E_{P T O}=F S$

where $F$ is the damping force, and $\mathrm{S}$ is the distance of the buoy movement.

And the extraction of PTO in pendulum device is calculated by

$E_{\text {PTO }}=T_{p t o} \varnothing$

where $T_{p t o}$ is the damping torque and $\varnothing$ is the rotation angle of the pendulum.

Fig.4 and Fig. 5 show how the power absorption of the buoy and pendulum respectively various with PTO damping for a regular wave with $T=1.96 \mathrm{~s}, H=12 \mathrm{~cm}$. For both devices, a single peak is observed in absorbed power as damping is varied. Also, the maximum power absorption is the same regardless of PTO types (here, it is $220 \mathrm{~J}$ for buoy, 455J for the Pendulum), although the relationship between power and damping is different. The constant damping type was judged as the more suitable one for the model tests of both devices as it has the softest trend (easy to control) and is convenient to setup.

The differences between the absorbed power calculated from the PTO and WHTO are below 3\% in both Fig. 4 and Fig.5 These differences are within the accuracy of the numerical model simulations. The similarity between absorbed power calculated by both approaches confirms that 
the assumption that $C=\frac{1}{8} \rho g L D N$ made in the theoretical derivation of WHTO is acceptable.

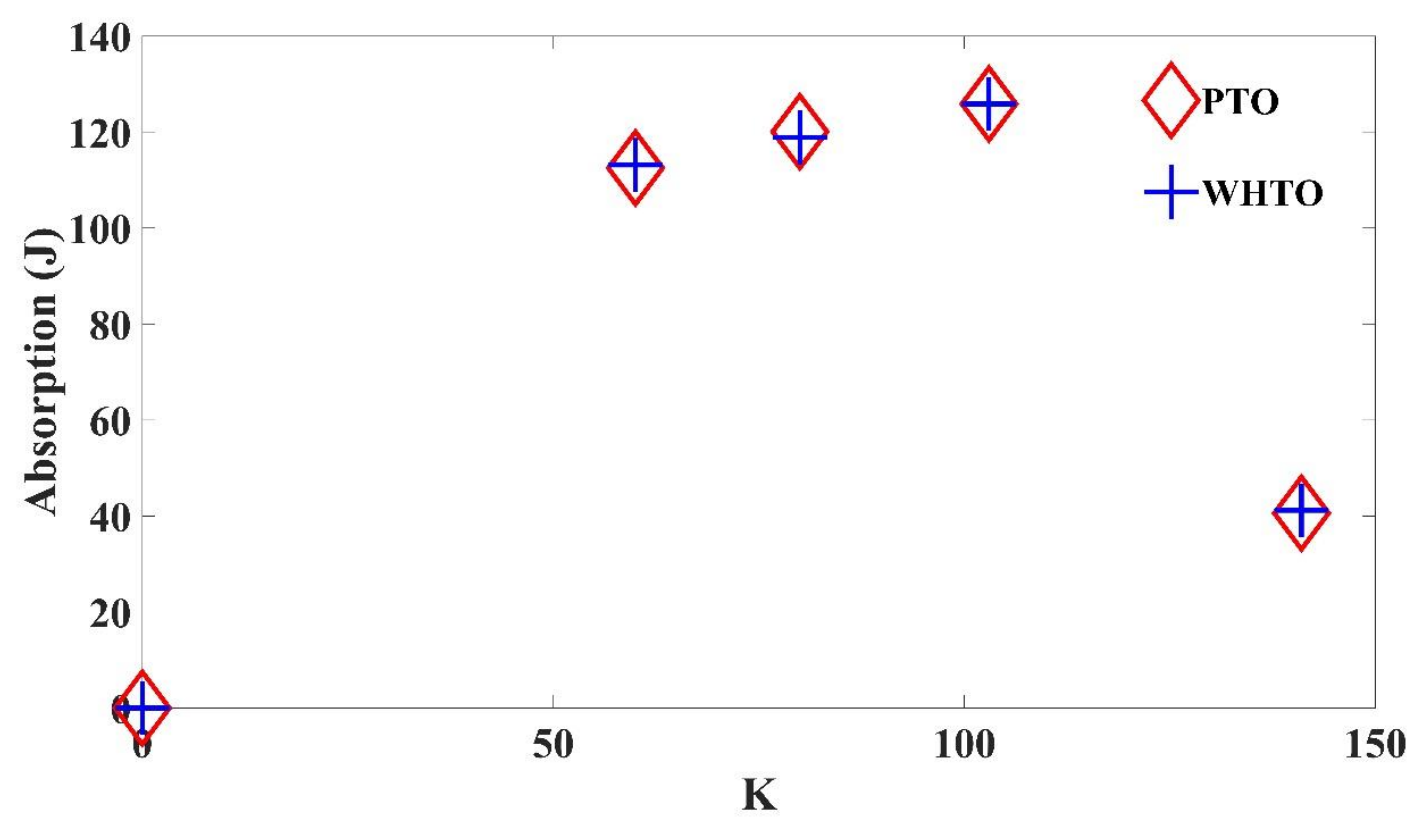

(a)

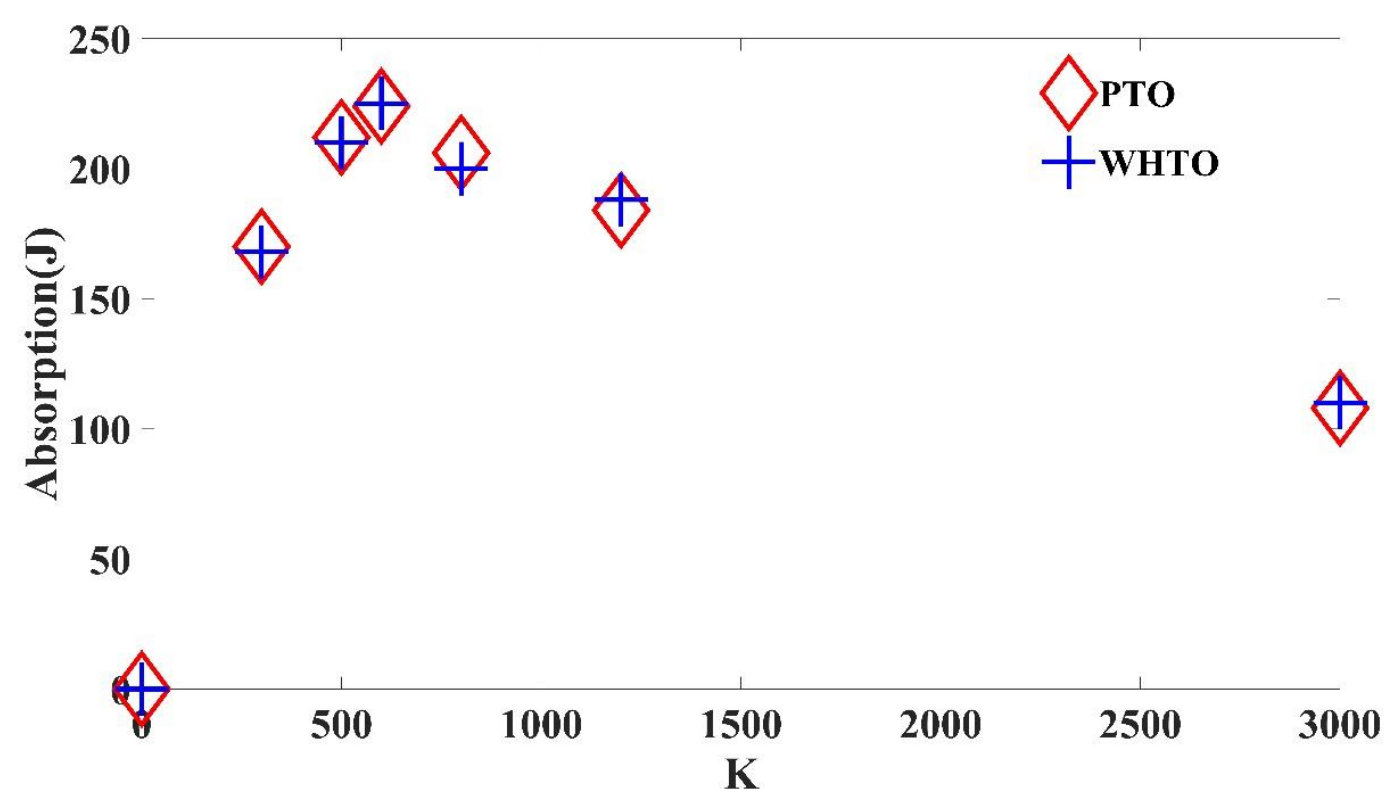

(b)

Fig.4 Energy absorbed calculated by WHTO and by PTO by heaving buoy with varying PTO damping for regular wave $T=1.96 \mathrm{~s} H=12 \mathrm{~cm}$. (a) Constant PTO damping (b) Linear PTO damping 


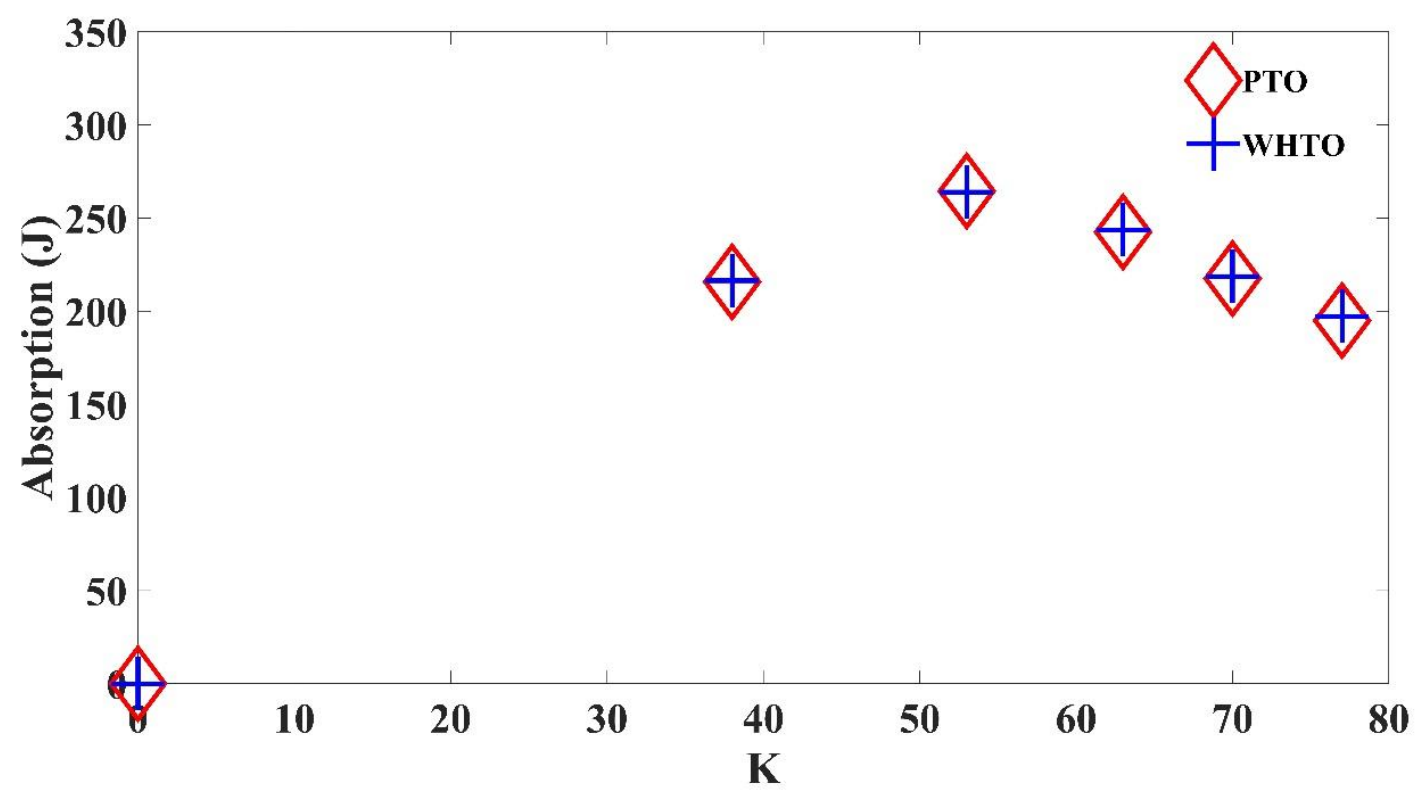

(a)

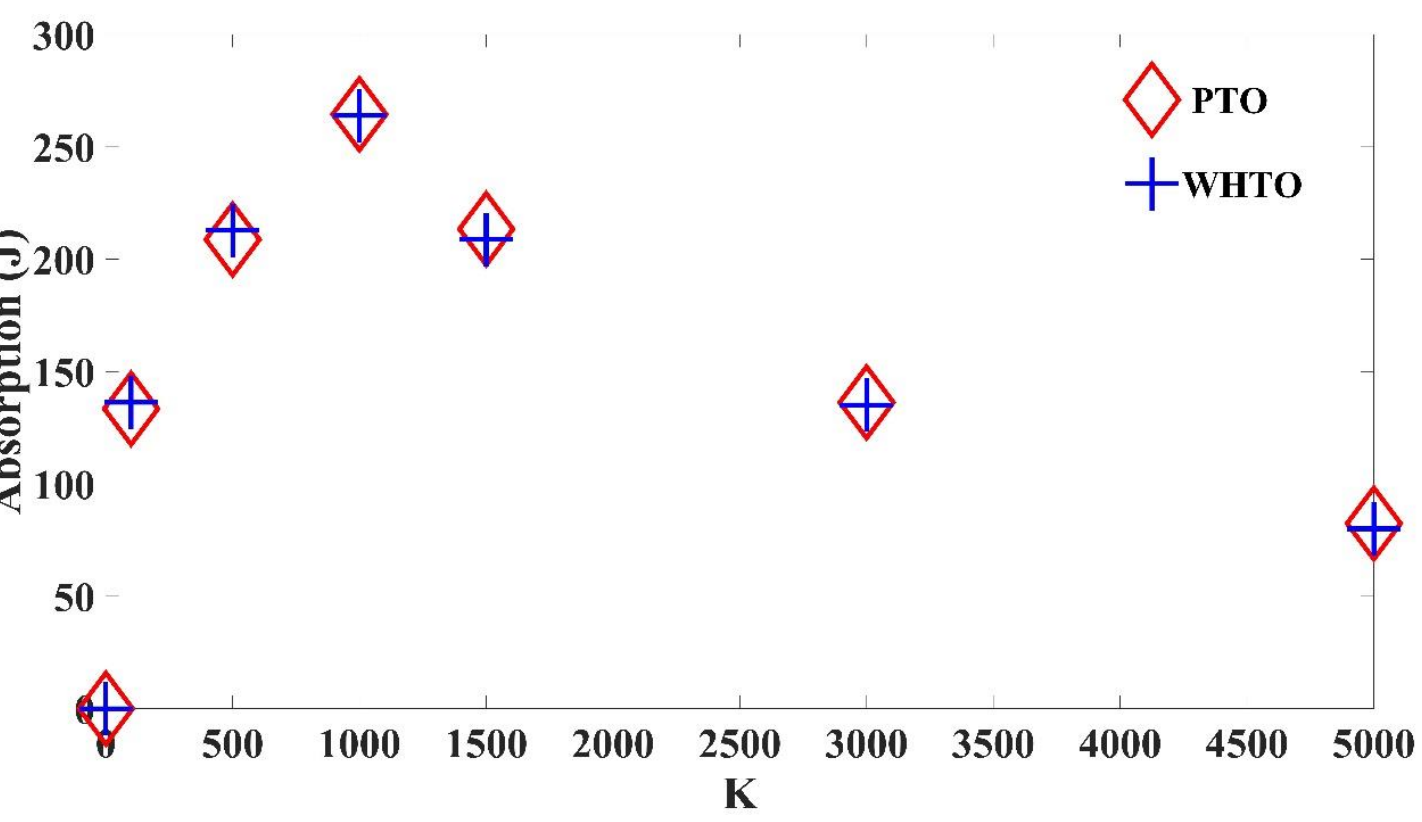

(b)

Fig.5 Energy absorbed calculated by WHTO and by PTO for pendulum device with varying PTO damping for regular wave $T=1.96 \mathrm{~s} H=12 \mathrm{~cm}$. (a) Constant PTO damping (b) Linear PTO damping 


\section{Experimental setup}

\subsection{Layout}

Model tests were carried out at 1:9 scale under Froude scaling of both a heaving buoy and pendulum type WEC. A $60 \mathrm{~m}$ long, $3 \mathrm{~m}$ wide, $1.5 \mathrm{~m}$ deep flume was used with a single-directional wave maker. Flume width was reduced to $0.8 \mathrm{~m}$ to reduce the impacts from wave diffraction. The distance from the wave maker to the physical models (both heaving buoy and pendulum) was $25 \mathrm{~m}$. The layout of the experiment can be seen in Fig.6.

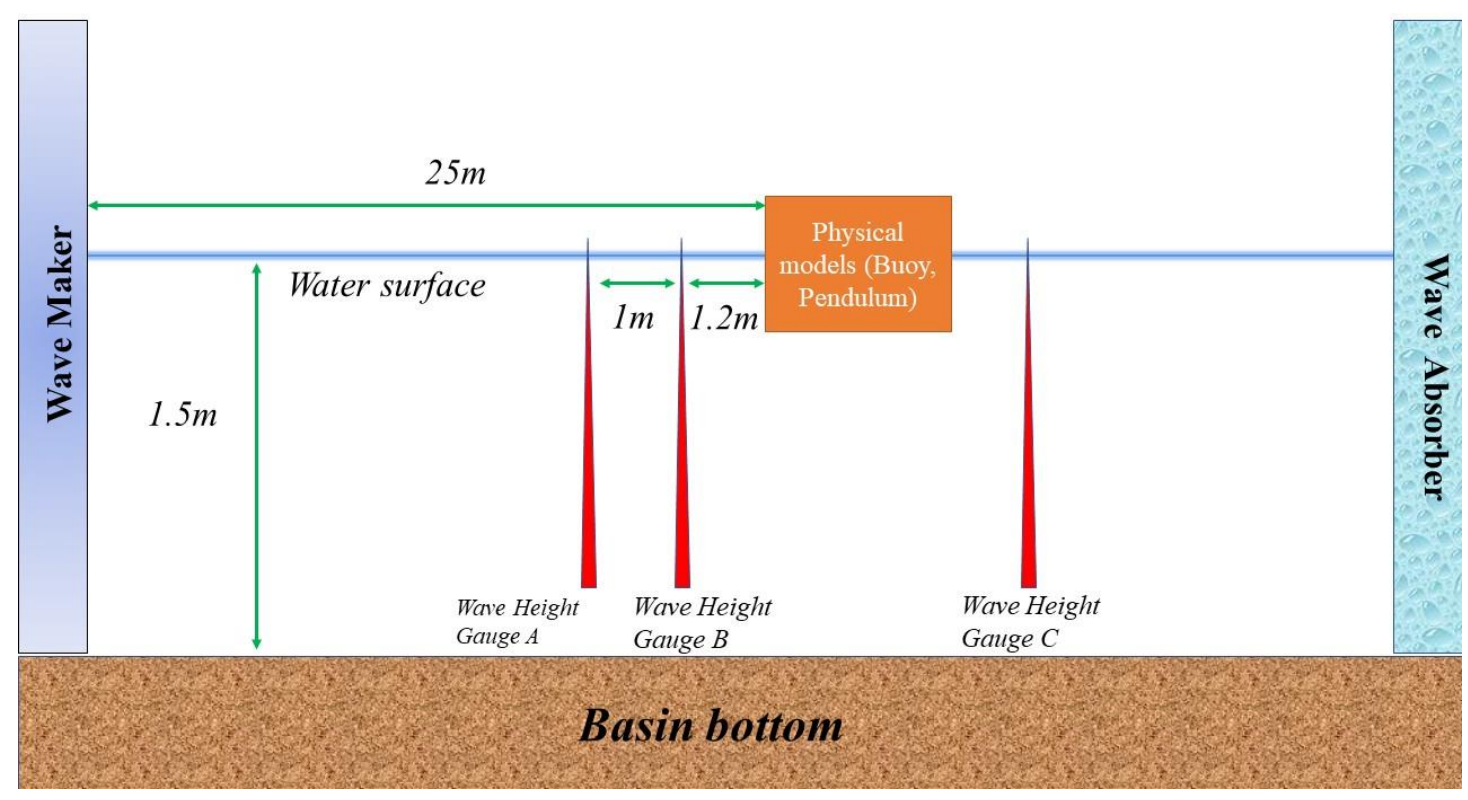

Fig.6 The layout of the experiment: three wave gauges are applied to collect the wave data behind and before the physical model

Surface elevation was measured at three locations using resistive wave gauges. Gauge C records surface elevation behind the device. The GODA method[20], also known as the two-point method, is applied to separate the incident and reflect wave using the Gauge A and Gauge B data. The distance between Gauge A and B was $1 \mathrm{~m}$, with Gauge A located $1.2 \mathrm{~m}$ from the device. The tank layout was also applied to the numerical wave tank.

The incident waves in north China are sheltered and blocked by the island chain at the western Pacific. Considering typical wave conditions in Qingdao and the experimental scale ratio and capability of the wave maker system [21], the wave parameters tested can be seen in the Table 3. 
Table 3 Wave parameters used during experimental tests on heaving buoy and pendulum device

\begin{tabular}{ll}
\hline Heaving buoy & Pendulum \\
\hline $1.96 \mathrm{~s} 12 \mathrm{~cm}$ & $1.96 \mathrm{~s} 12 \mathrm{~cm}$ \\
$2.51 \mathrm{~s} 12 \mathrm{~cm}$ & $1.96 \mathrm{~s} 20 \mathrm{~cm}$ \\
& $1.4 \mathrm{~s} 14 \mathrm{~cm}$ \\
\hline
\end{tabular}

\subsection{PTO}

A constant damping type PTO was applied to both physical models in the form of a clump weight lifting mechanical structure. The gear box (Fig.7), consisting of five gears, two one-way bearings, one input shaft, one output shaft, and a winch, converting reciprocating rotation generated by the WEC to one-way rotation, lifting the clump weight by a winch. The one-way bearing and gear were expected to face very high torque during the test and so they were made from titanium alloy.

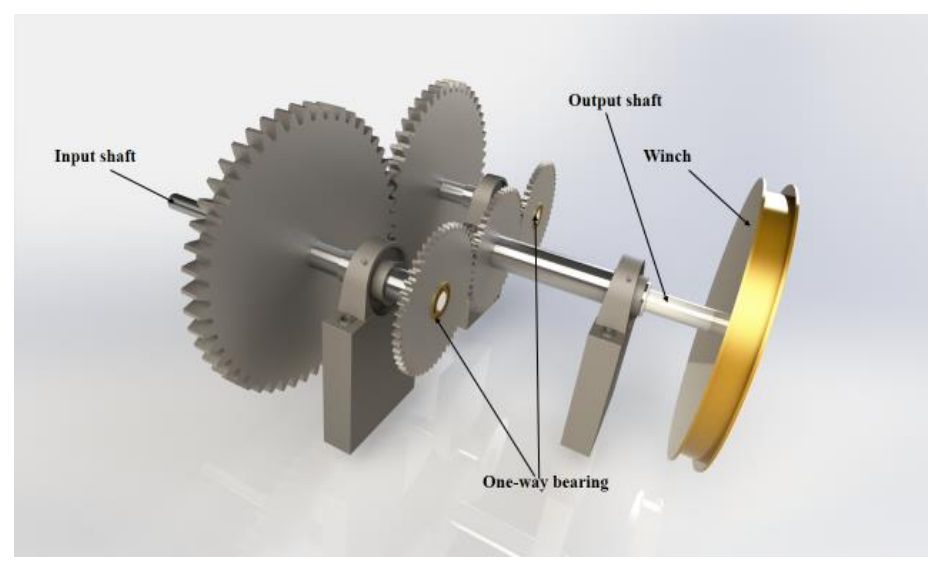

(a)

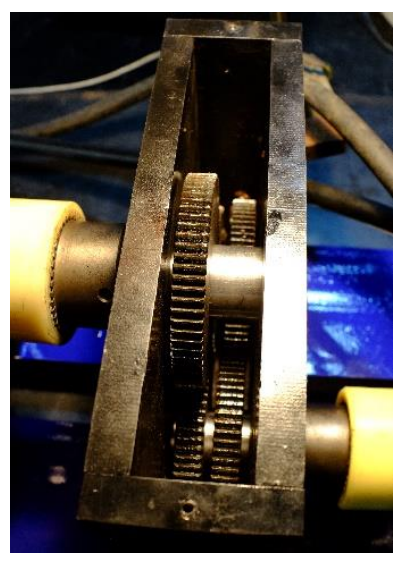

(b)

Fig.7 One-way gear box used during experimental tests; (a) structure diagram of the gear box and

$$
\text { (b) gear box used }
$$

To understand the damping of the device, the transmission efficiency of the gear box was measured using a torque sensor and an electric motor (Fig.8a). The PTO system input energy $\left(E_{\text {input }}\right)$ is recorded by torque sensor, and the output energy $\left(E_{\text {output }}\right)$ is measured by the change in height of the clump weight. The efficiency $\eta_{P}$ can be presented as: $\eta_{P}=\frac{E_{\text {output }}}{E_{\text {input }}}$. 
Fig.8.b shows the efficiency under the different damping (clump weight mass). The electric motor operated at a constant power and therefore the changes in damping resulted in variations in rotation speed. As shown by Fig 8.b, the efficiency is 55\% with an acceptable fluctuation.

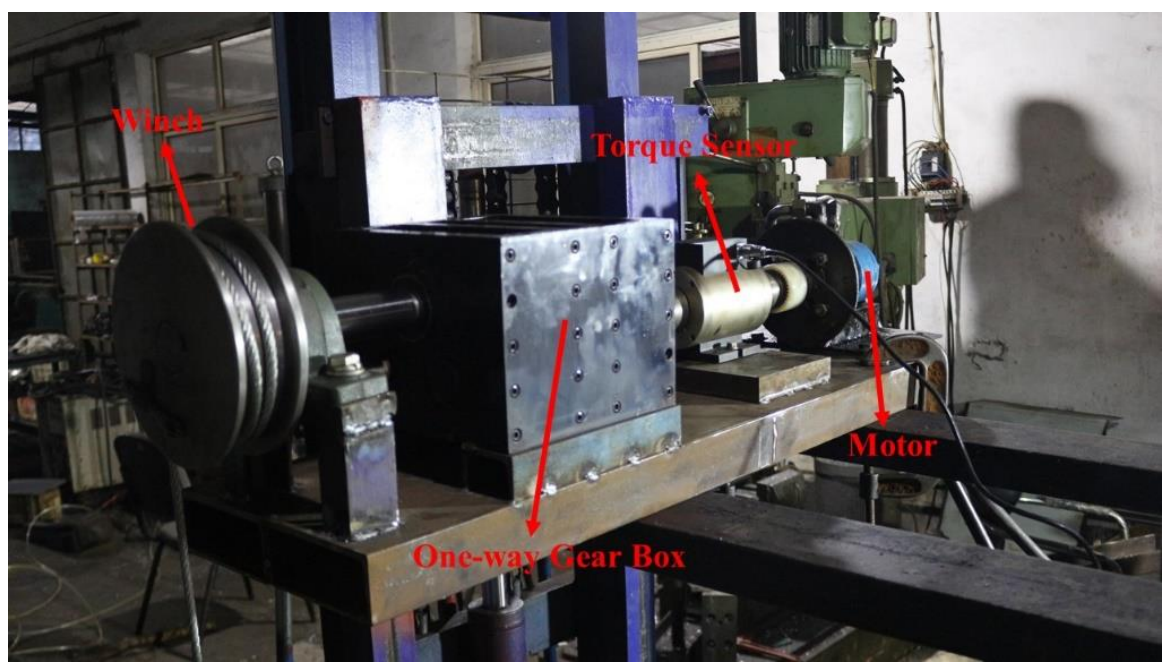

(a)

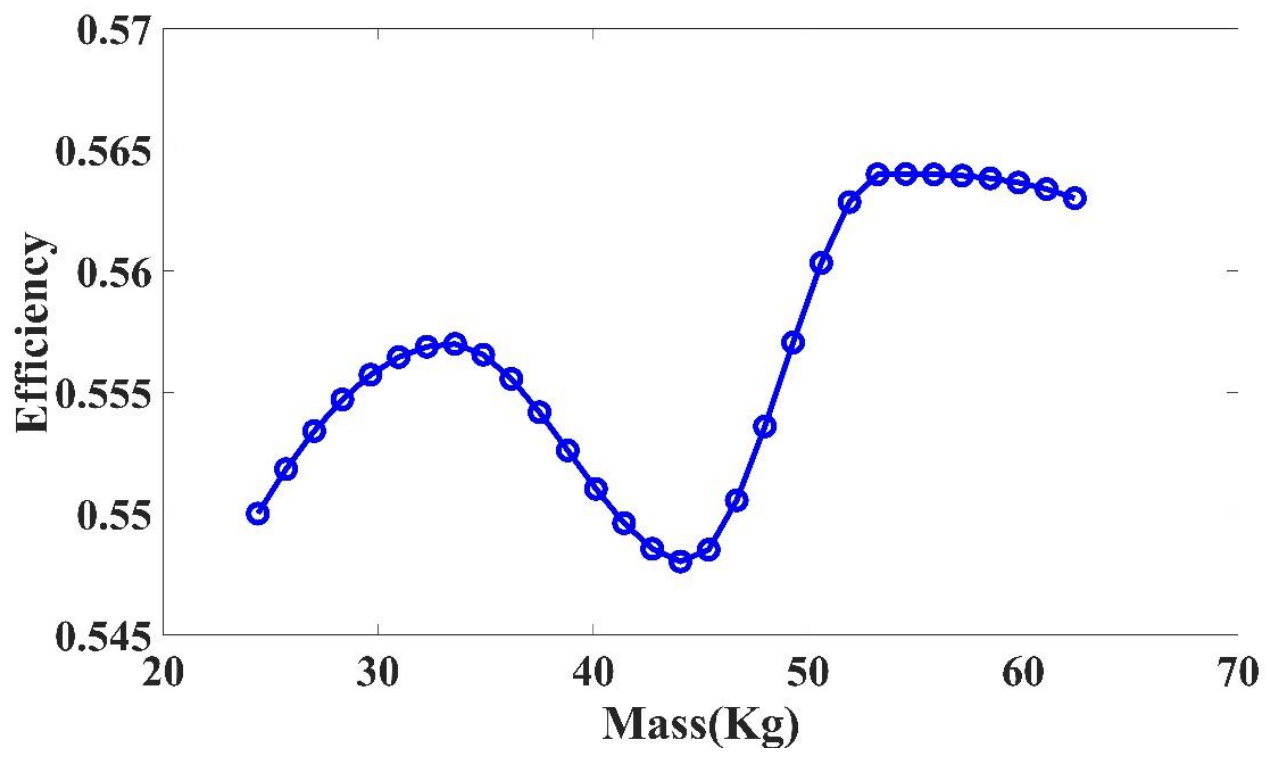

(b)

Fig.8 Transmitted efficiency test of experimental PTO arrangement. (a) set-up of test, (b) measurement of efficiency, with different damping values

The motor tests were also used to validate the assumption that the gear-box - clump weight PTO model provided constant damping. Fig. 9 shows the curve of damping type was an approximate square wave, validating the constant damping caused by the clump weight. The damping value also has an acceptable fluctuation when the device is in a reciprocating motion. 


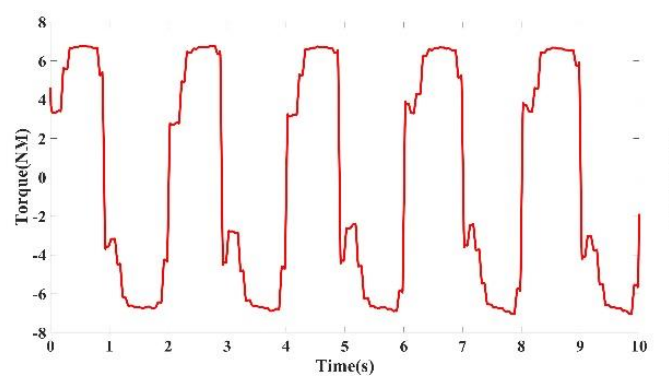

(a)

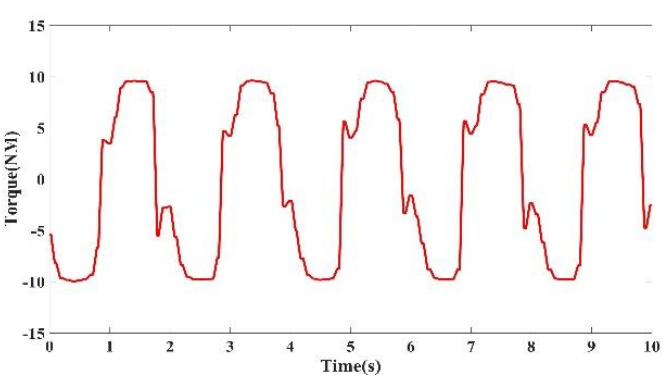

(b)

Fig.9 Constant damping produced by the lifting weight system: (a) The damping torque on the winch is 7 NM. (b) The damping torque on the winch is $10 \mathrm{NM}$

The mass of the clump weight was varied from $10 \mathrm{Kg}$ to $120 \mathrm{Kg}$ in the pendulum cases and between $1 \mathrm{Kg}$ and $25 \mathrm{Kg}$ for the buoy. The absorbed energy is proportion to the lifting height of the clump weight in a certain time. The maximum number of waves is dependent on the wave speed, ensuring the wave reflected by the physical model will not reach the wave maker. In this test, the regular waves are employed for the experimental studies.

\subsection{The model of heaving buoy}

The heaving buoy had a density of $600 \mathrm{Kg} / \mathrm{m}^{3}$ and was a $700 \mathrm{~mm}$ long, $500 \mathrm{~mm}$ wide and 350 $\mathrm{mm}$ high cuboid. The buoy is designed as a cuboid to limit waves radiation and diffraction effects. At the four corners of the buoy, there are four linear bearings to ensure the buoy heaves along the four light bars with very little resistance. A rack was installed at the central point of the upper surface of the buoy. As the buoy heaved, the rack drove the one-way gear box to lift the clump by a winch. The details can be seen in the Fig.10.

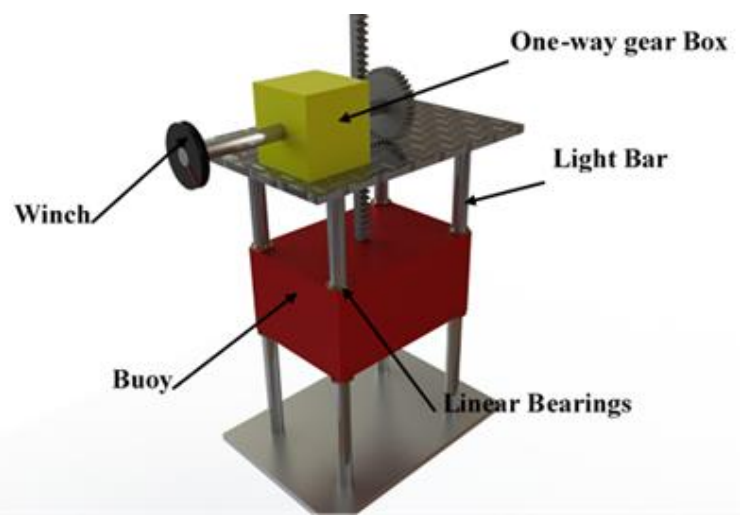

(a) 


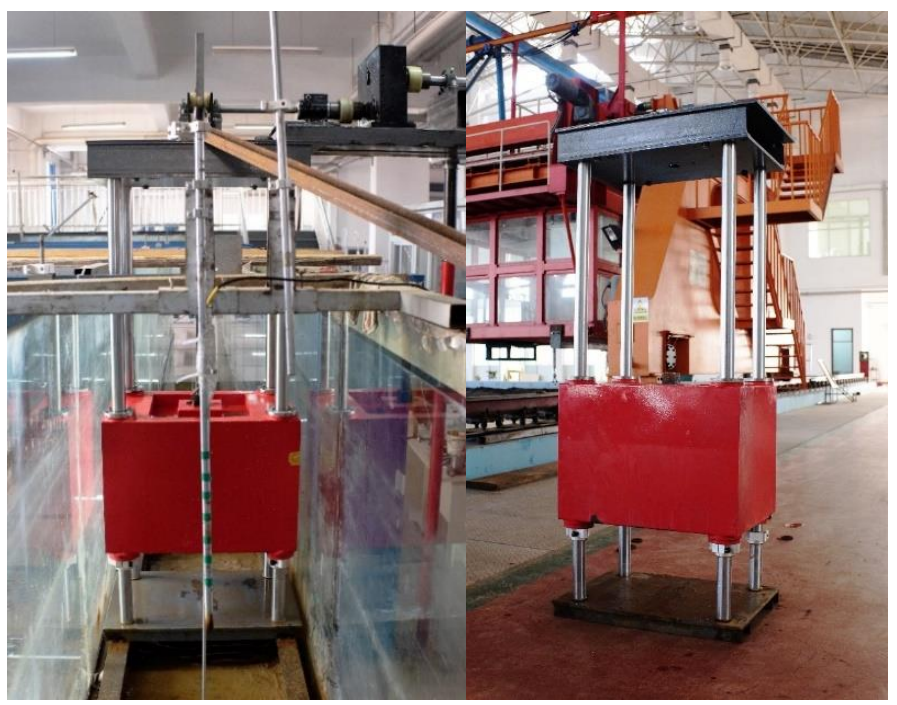

(b)

Fig.10 Structure diagram of Heaving buoy WEC: (a). Heaving buoy design sketch. (b). Heaving buoy physical model

\subsection{The model of pendulum}

The pendulum plate was $150 \mathrm{~mm}$ long, $700 \mathrm{~mm}$ wide and $700 \mathrm{~mm}$ high and made from aluminum alloy. The plate was connected to the flume base with a shaft which was connected to the PTO via a gear and chain. The details can be seen in the Fig. 11.

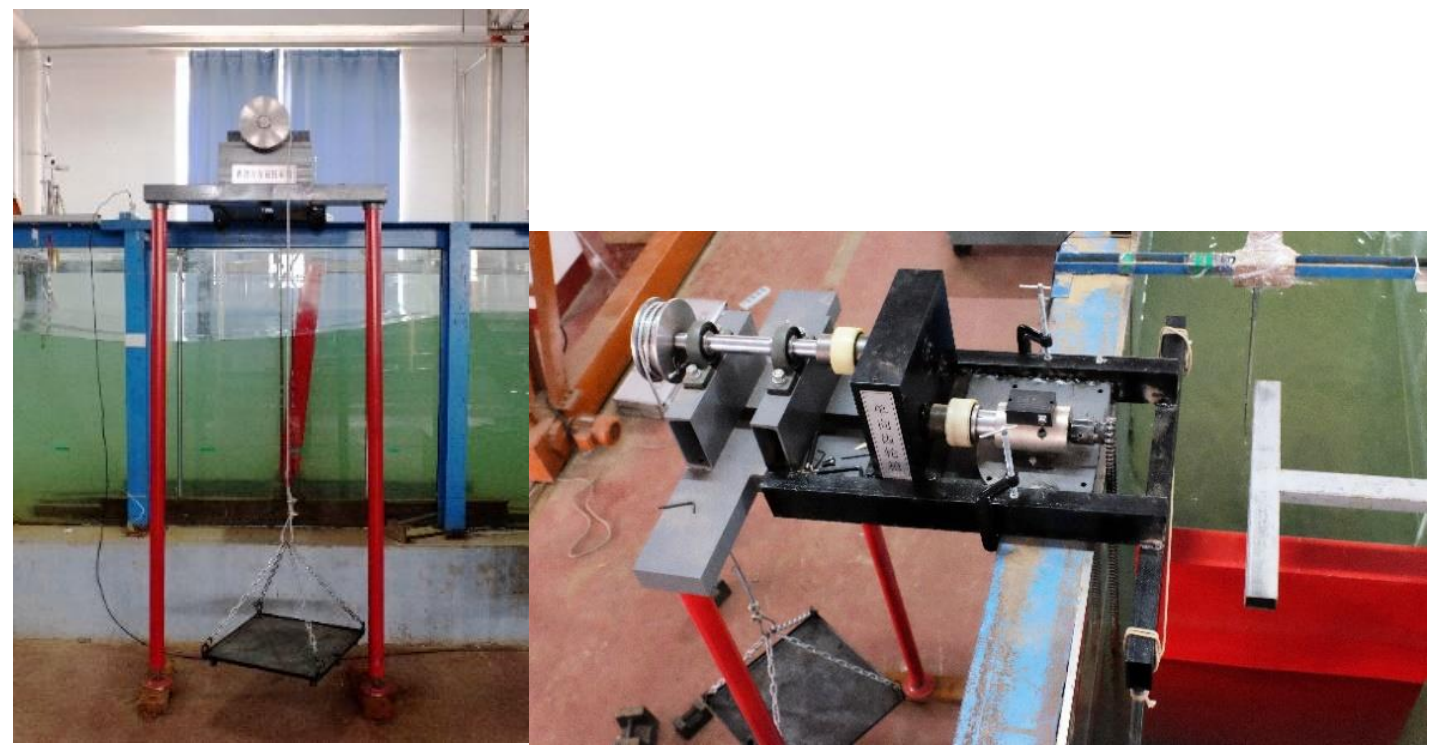

(a) 


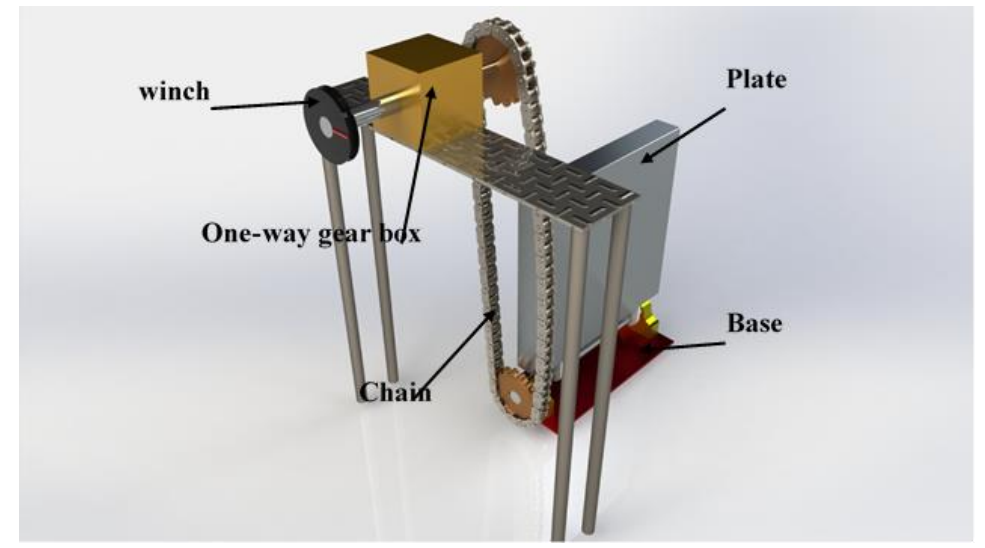

(b)

Fig.11 Structure diagram of Pendulum WEC (a). Pendulum physical model includes the pendulum and the PTO connections. (b). Pendulum design sketch

\section{Results and Discussions}

\subsection{The differences between WHTO and PTO}

\section{Heaving buoy}

The principle of the WHTO method is to calculate the power extracted by the device by measuring the wave heights. Fig.12 shows the incident wave, reflected wave and the transmitted wave height with different damping values. The incident and reflected wave heights were calculated by GODA method while the transmitted one was recorded by the Gauge C. All the wave heights were analyzed by the mean value method. 


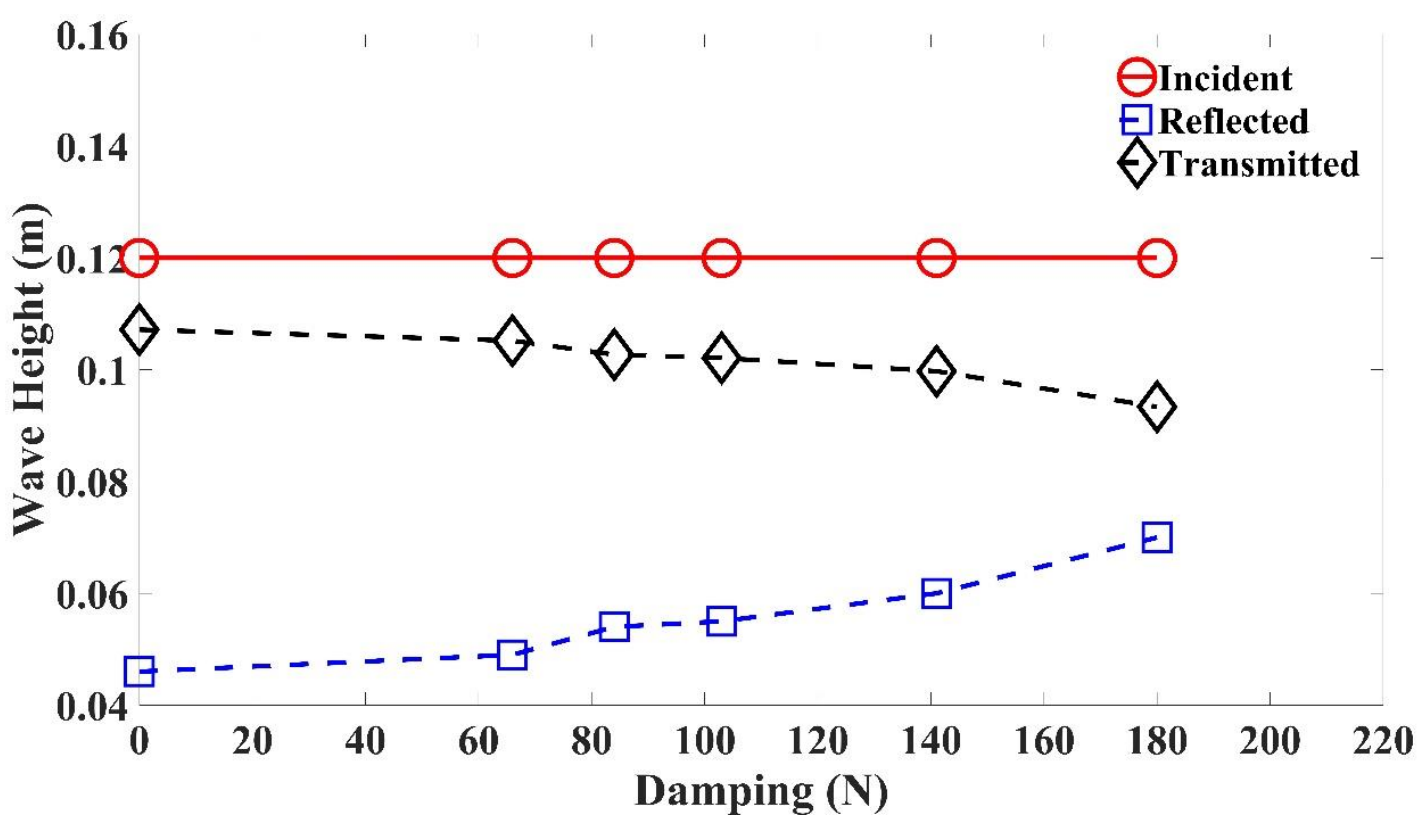

(a)

0.16

0.14

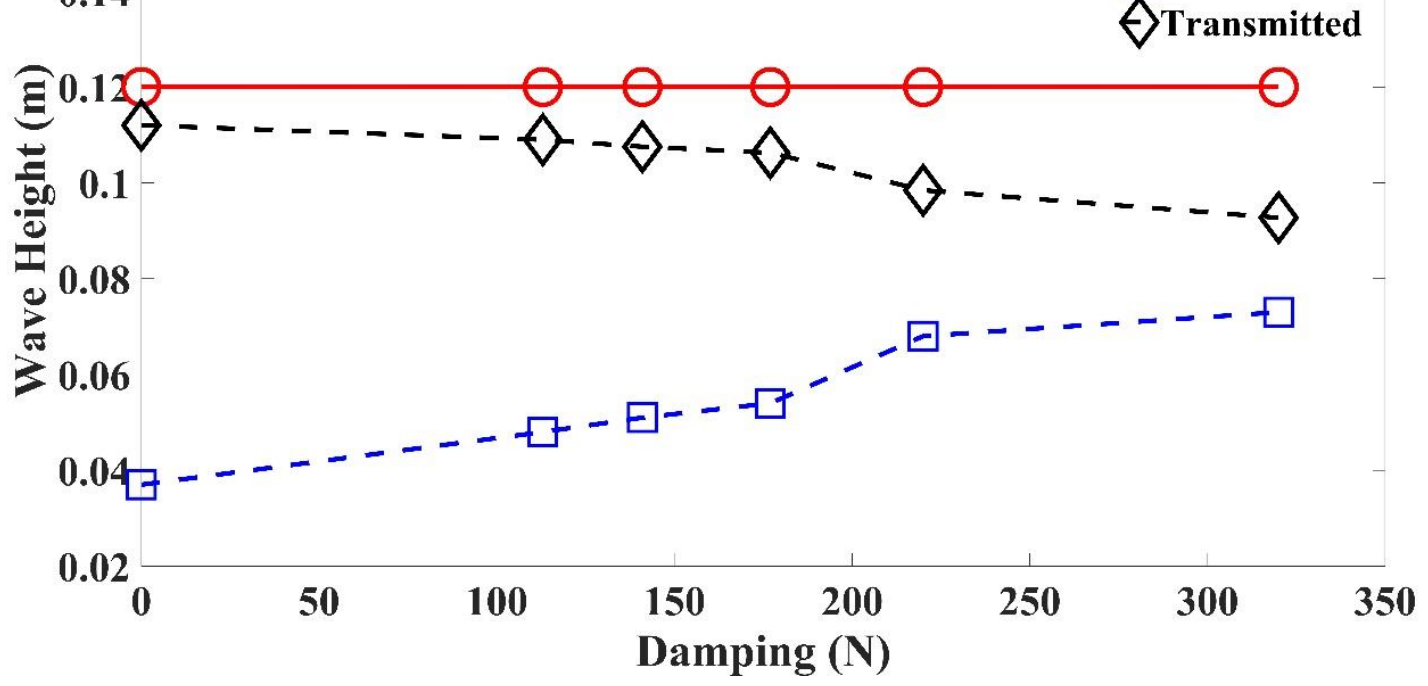

(b)

Fig.12 Incident wave height, reflected wave height and the transmitted wave height: (a). The wave condition is $T=1.96 \mathrm{~s} H=12 \mathrm{~cm}$. (b). The wave condition is $T=2.51 \mathrm{~s} H=12 \mathrm{~cm}$

Before testing in the wave tank, incident wave height was calibrated. Minor fluctuations in the incident wave height were observed once reflected waves reached the wave maker. All analysis was conducted before this occurred, ensuring the incident wave height was the same for each damping value tested. As damping increased, the reflected wave height increased while the transmitted wave height decreased. However, when the damping reached $180 \mathrm{~N}$ the device could no longer move. 
Overtopping effects led to a growth for the transmitted wave height. The same phenomenon occurs in the 2.51s cases (shown by Fig.12.b) but is more obvious.

Fig.13 shows the absorbed power calculated from the PTO and the WHTO, respectively. When calculating the energy extracted by the PTO, the measured $\eta_{p}$ was applied to account for the mechanical energy loss in the one-way gear box. The power loss from diffraction effects were measured using the WHTO technique when the PTO system was disconnected and so no damping was applied and when damping levels were large enough to prevent device motion (experienced in the $\mathrm{T}=1.96 \mathrm{~s}, \mathrm{H}=12 \mathrm{~cm}$ case when damping was $180 \mathrm{~N}$ ). The energy loss was found to be nearly constant in these two cases. This power loss has been removed from the power calculated using the WHTO method.

The difference between PTO and WHTO were larger than in the simulations for the 1.96s case (Fig.13 a), where the power calculated from the PTO was consistently smaller than the WHTO result. This is believed to be due to mechanical losses within the PTO system, not accounted for in the calibration of the gearbox efficiency. Some wave breaking when the wave interacted with the buoy was also observed during these wave conditions, which would have potentially increased the measured WHTO value. However, in 2.51s case (Fig. 13b), the wave breaking is not obvious, leading a better agreement between the absorption measured by PTO and the WHTO. Under two lowest damping values, the PTO extraction is a slightly larger than the WHTO extraction. This is possibly due to the effects of overtopping of the buoy observed during tests under these wave conditions. This overtopping would result in a slight increase in the wave height measured behind the buoy, thereby reducing the WHTO measurement. 


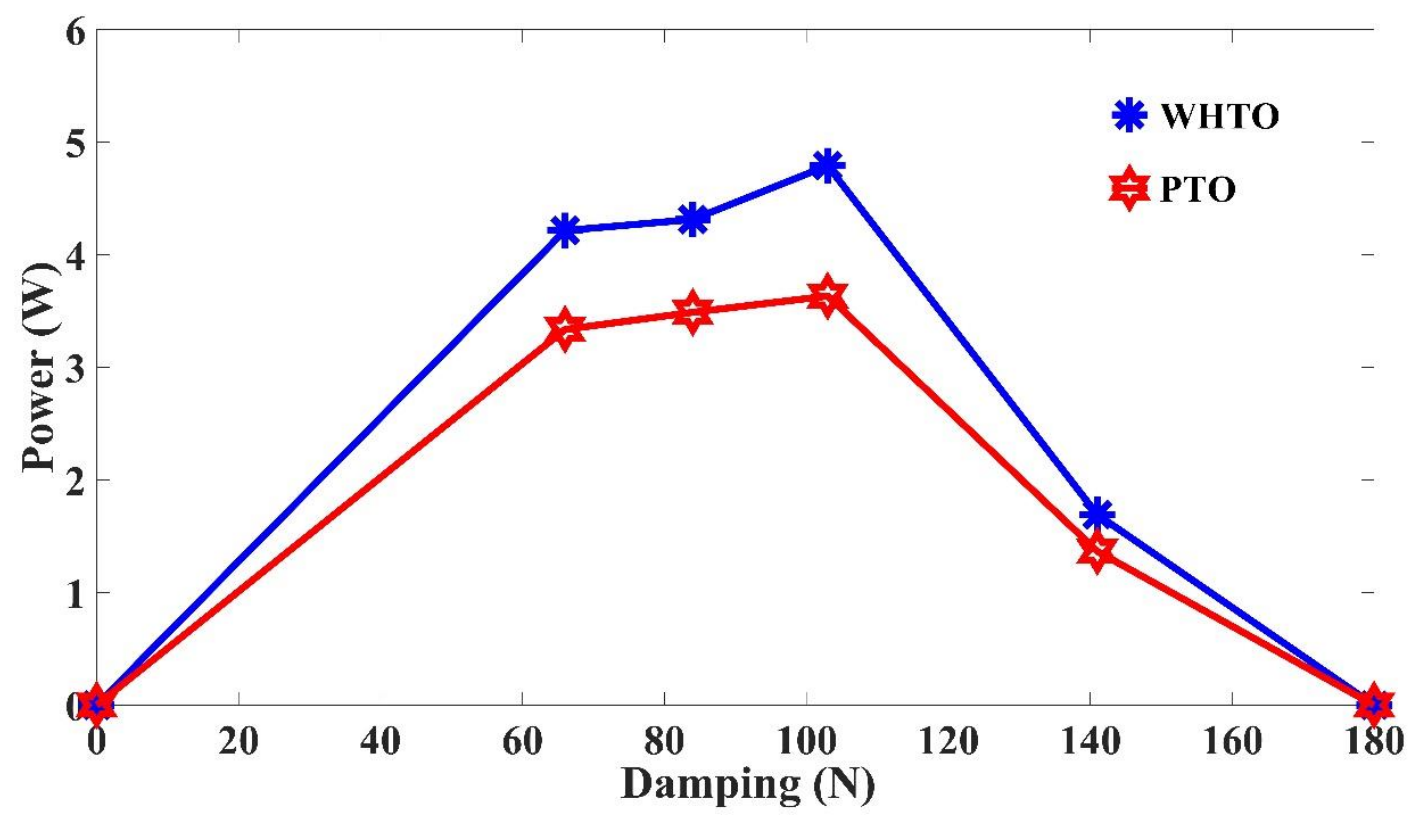

(a)

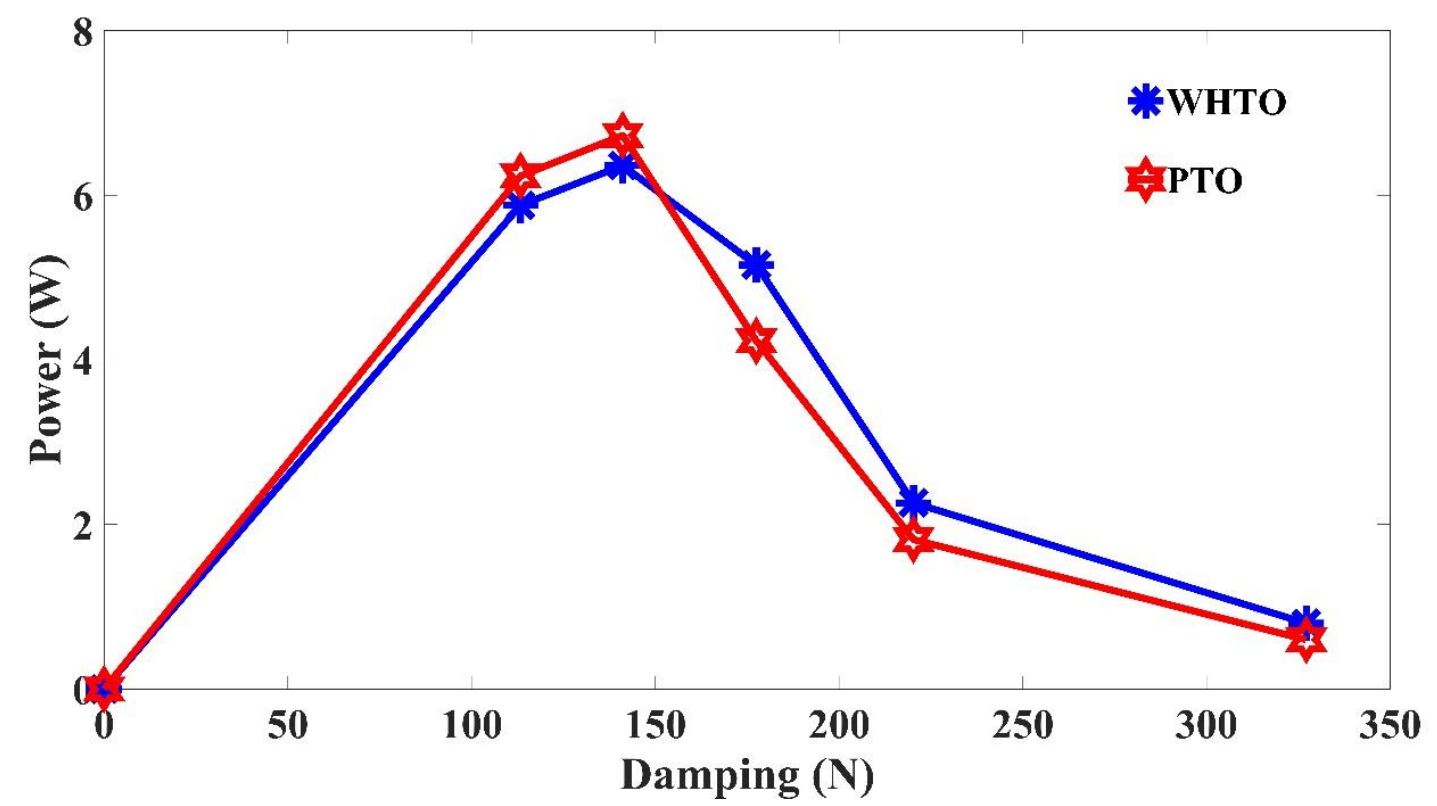

(b)

Fig.13 The power calculated by PTO and WHTO for the heaving buoy (a) The wave condition is $T=1.96 \mathrm{~s} H=12 \mathrm{~cm}$ (b). The wave condition is $T=2.51 \mathrm{~s} H=12 \mathrm{~cm}$

\section{Pendulum}

During the pendulum tests, the wave did not break, and the other energy losses could be ignored. Fig 14 show the three types of wave height with different damping values under different input conditions. The torque could be presented as: $T_{M}=M g R$, where $\mathrm{R}$ is the radius of the winch. 


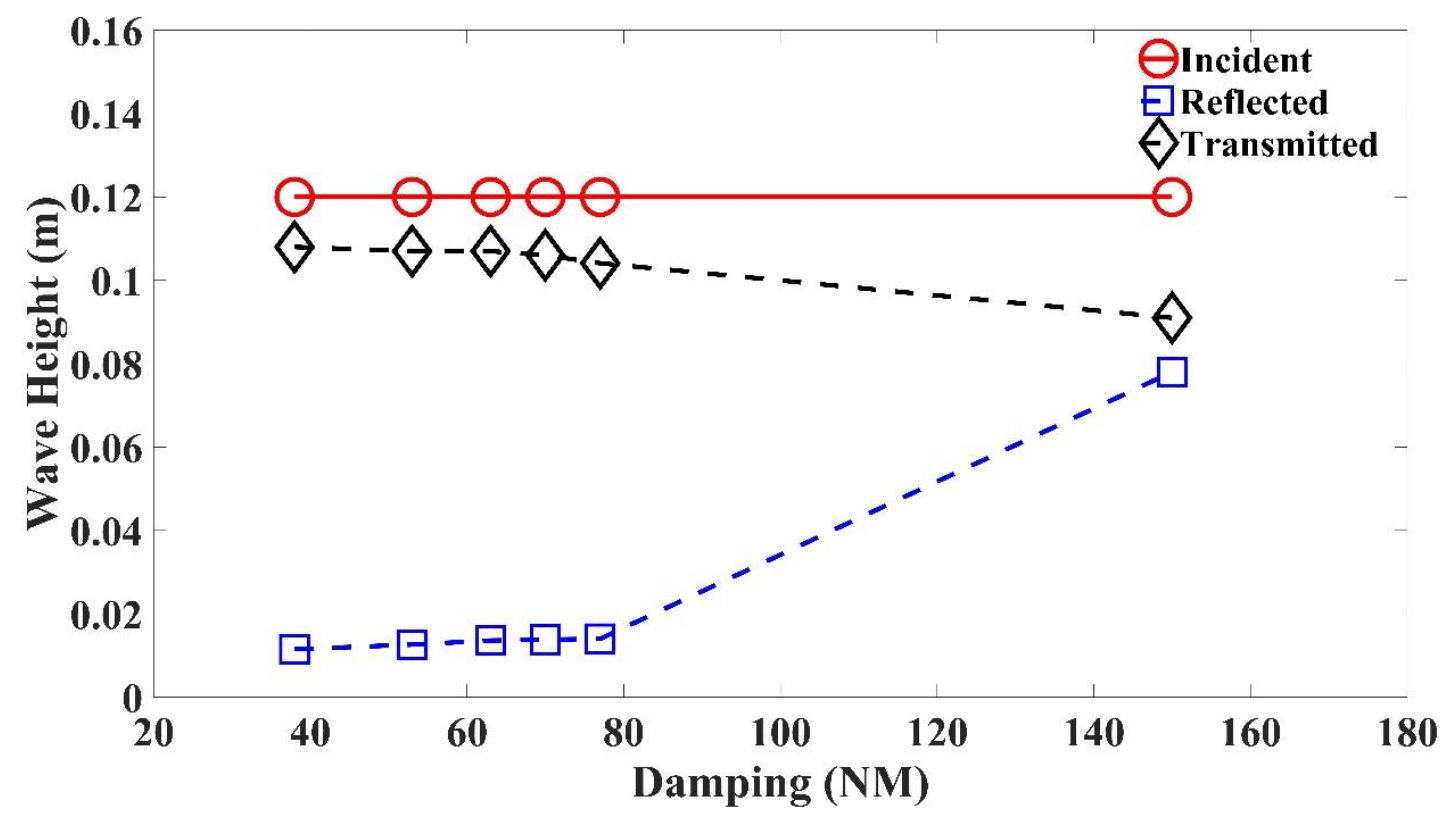

(a)

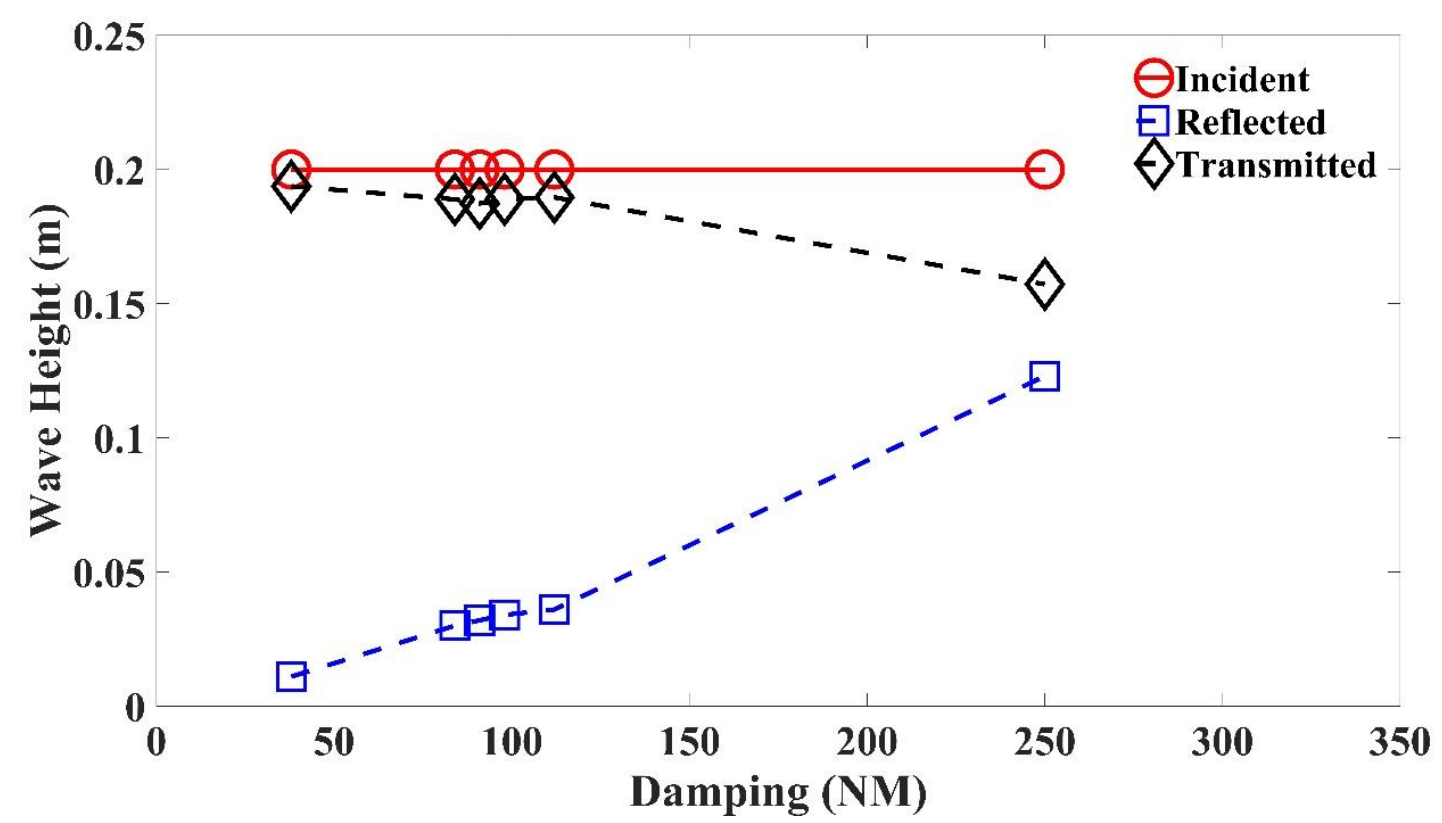

(b)

Fig.14 Incident wave, reflected wave and the transmitted wave (a). The wave condition is $T=$

$$
1.96 \mathrm{~s} H=12 \mathrm{~cm} \quad \text { (b). The wave condition is } T=1.96 \mathrm{~s} \mathrm{H}=20 \mathrm{~cm}
$$

Shown by Fig.14, the incident wave height was still a constant value. Like the buoy cases, the reflected wave height increases with increasing damping (more obvious in the higher wave height cases). When the damping is large enough to fix the device (150NM for $H=12 \mathrm{~cm}, 250 \mathrm{NM}$ for $H=20 \mathrm{~cm}$ ), the pendulum blocked the flume. The transmitted wave height was caused by the wave overtopping. The extracted energy calculated by the PTO and WHTO are shown in Fig.15. 
Compared with the buoy case, the power calculated from the PTO and WHTO show good agreement during both wave conditions and at all damping values. It should be noted that unlike the buoy case wave breaking and overtopping were not observed during the pendulum tests. It can also be seen that the optimal damping value is not a constant with different wave heights.

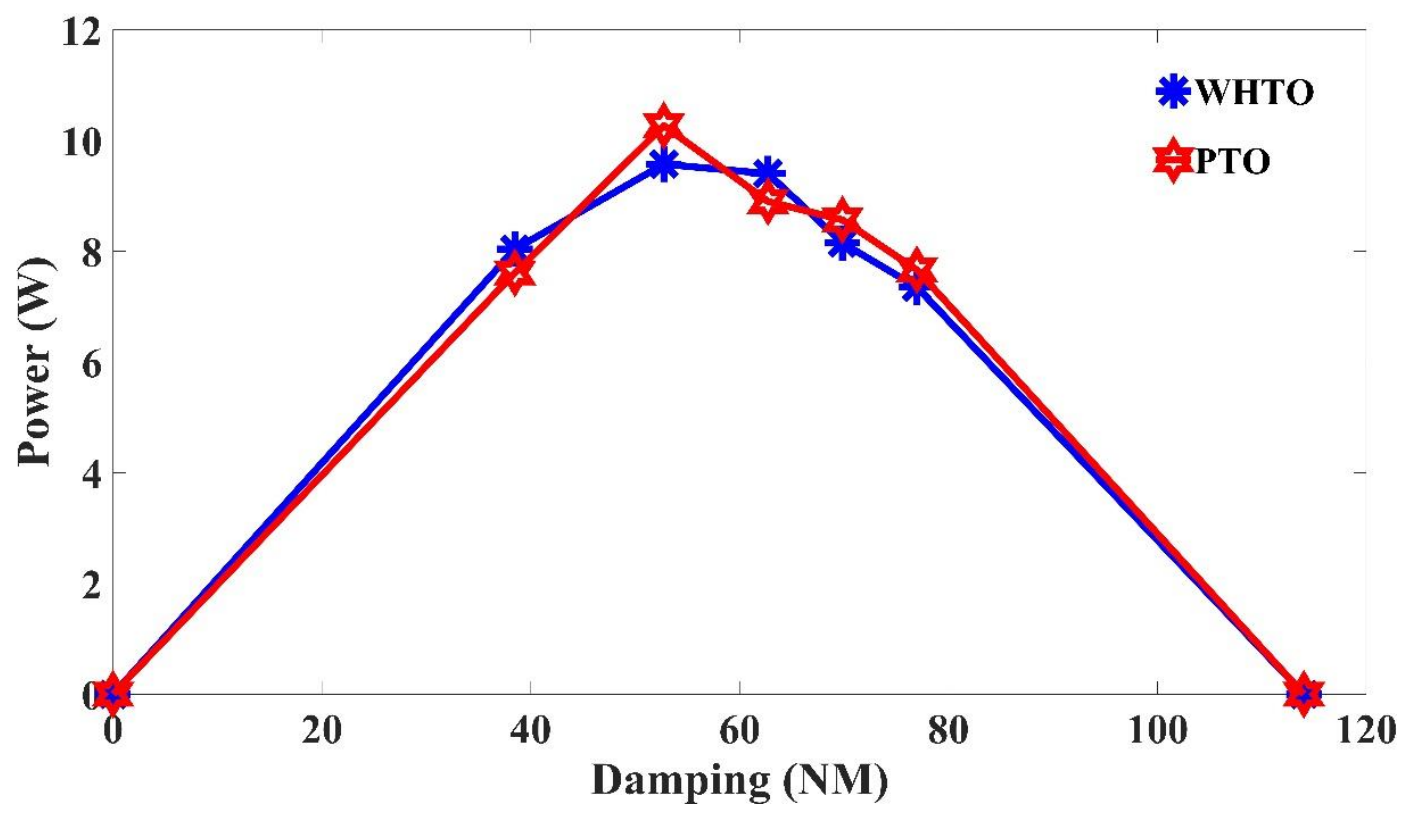

(a)

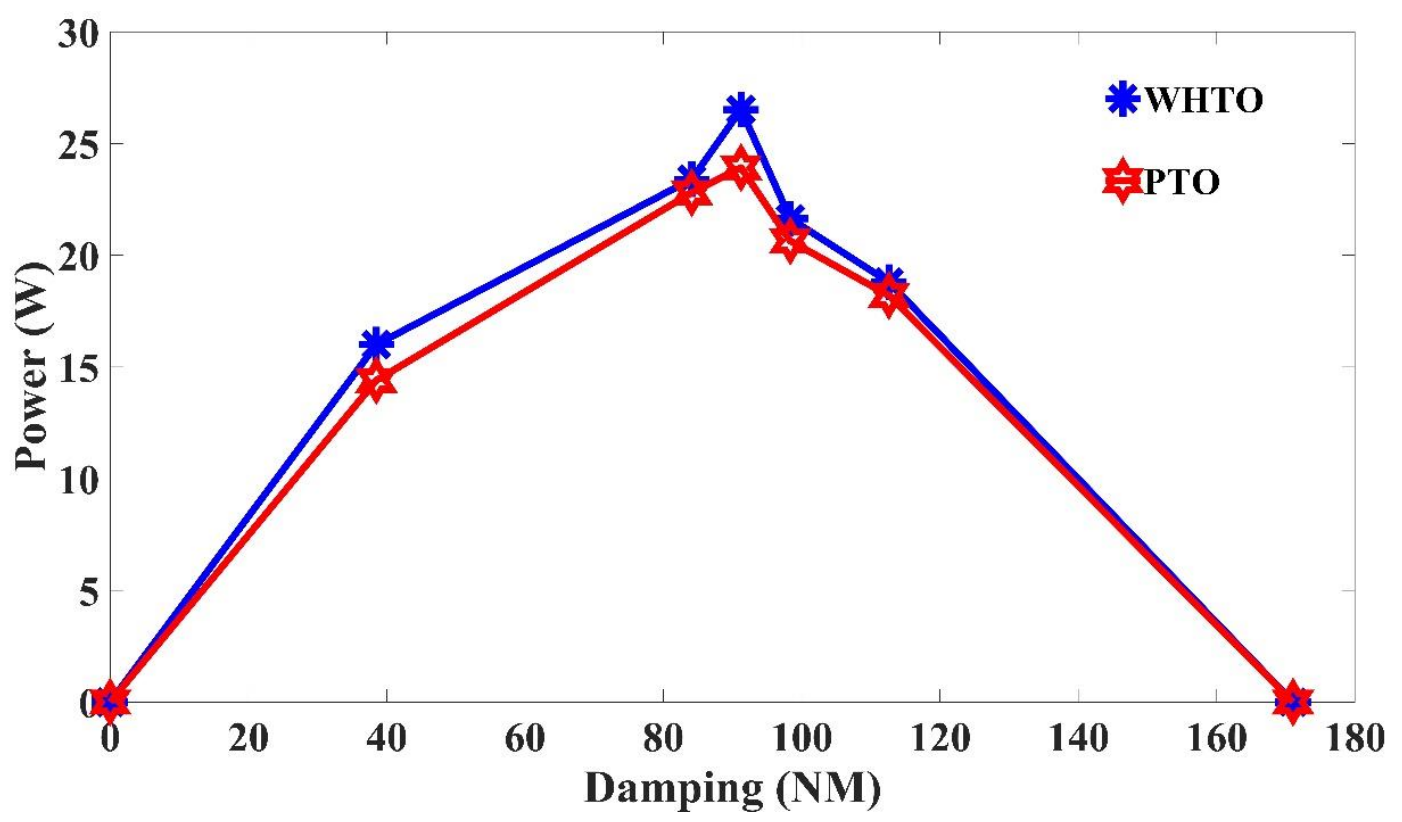

(b)

Fig.15 PTO and WHTO in Pendulum (a). The wave condition is $T=1.96 \mathrm{~s} H=12 \mathrm{~cm}$ (b). The wave condition is $T=1.96 \mathrm{~s} H=20 \mathrm{~cm}$ 


\subsection{The efficiency calculated by WHTO and PTO}

The heaving buoy and the pendulum are symmetric. Based on[22][23], the maximum absorption efficiency for the symmetric oscillating body is $50 \%$ in $2 \mathrm{D}$ flume. Fig. 16 shows the whole efficiency of the two devices under the same wave condition $(T=1.96 \mathrm{~s}, \mathrm{H}=12 \mathrm{~cm})$. The maximum efficiency (by WHTO) for the pendulum is $17 \%$ while the heaving buoy it is only $8.5 \%$, demonstrating that in these wave conditions the pendulum performed better.

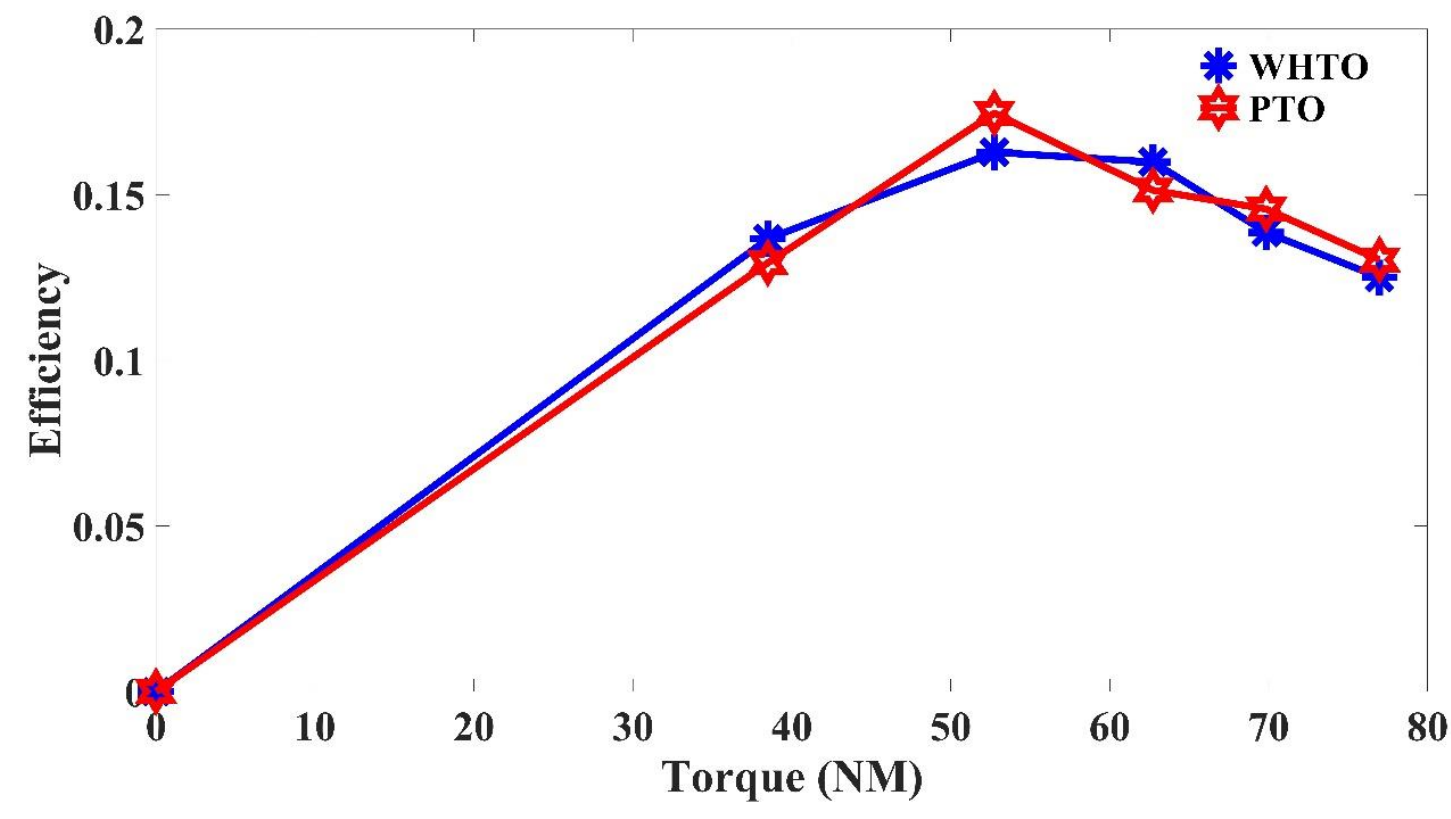

(a)

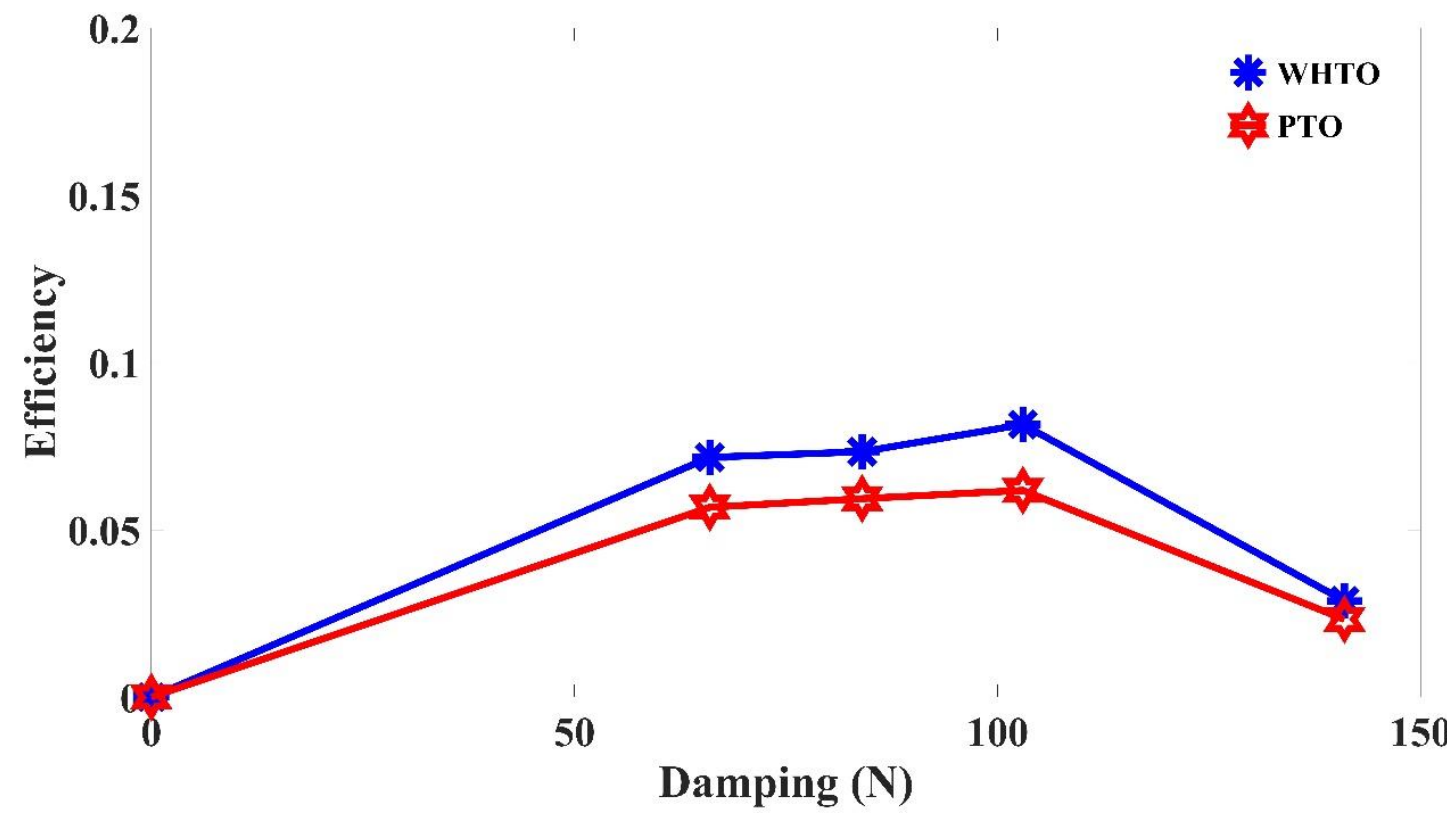

(b) 
Fig. 16 The efficiency of two devices: (a). The Pendulum device with a maximum efficiency $17 \%$.

(b). The Heaving buoy device with a maximum efficiency $8.5 \%$

\subsection{Comparison between theoretical and experimental results}

This part compares the absorption in simulation and physical model for the heaving buoy and pendulum $(T=1.96 \mathrm{~s} H=12 \mathrm{~cm})$, respectively. Fig. $17 \mathrm{~b}$ demonstrates that for the pendulum WEC the numerical model and physical results are in good agreement. The trend in power with increasing damping is correctly predicted by the model. The magnitude of the power is slightly over predicted by the numerical model (by an average of $5 \%$ ). This is believed to be due to additional losses within the experiment not accounted for in the numerical model.

Fig. 17a shows that for the heaving buoy the numerical and physical results have a less good agreement compared to the pendulum. The trend in absorbed power with damping is correctly modelled, however the magnitude of absorbed power is significantly greater in the numerical model. This difference is $20 \%$ for power calculated by the PTO and $7 \%$ for the power calculated by WHTO. In section 5.1 it was proposed that the difference between PTO and WHTO measurement in the model tests was due to mechanical losses reducing the PTO measurement and wave breaking increasing the WHTO measurement. The results in Fig.17a suggest that the mechanical losses are more significant, as unlike wave breaking these are not simulated within the numerical model. 


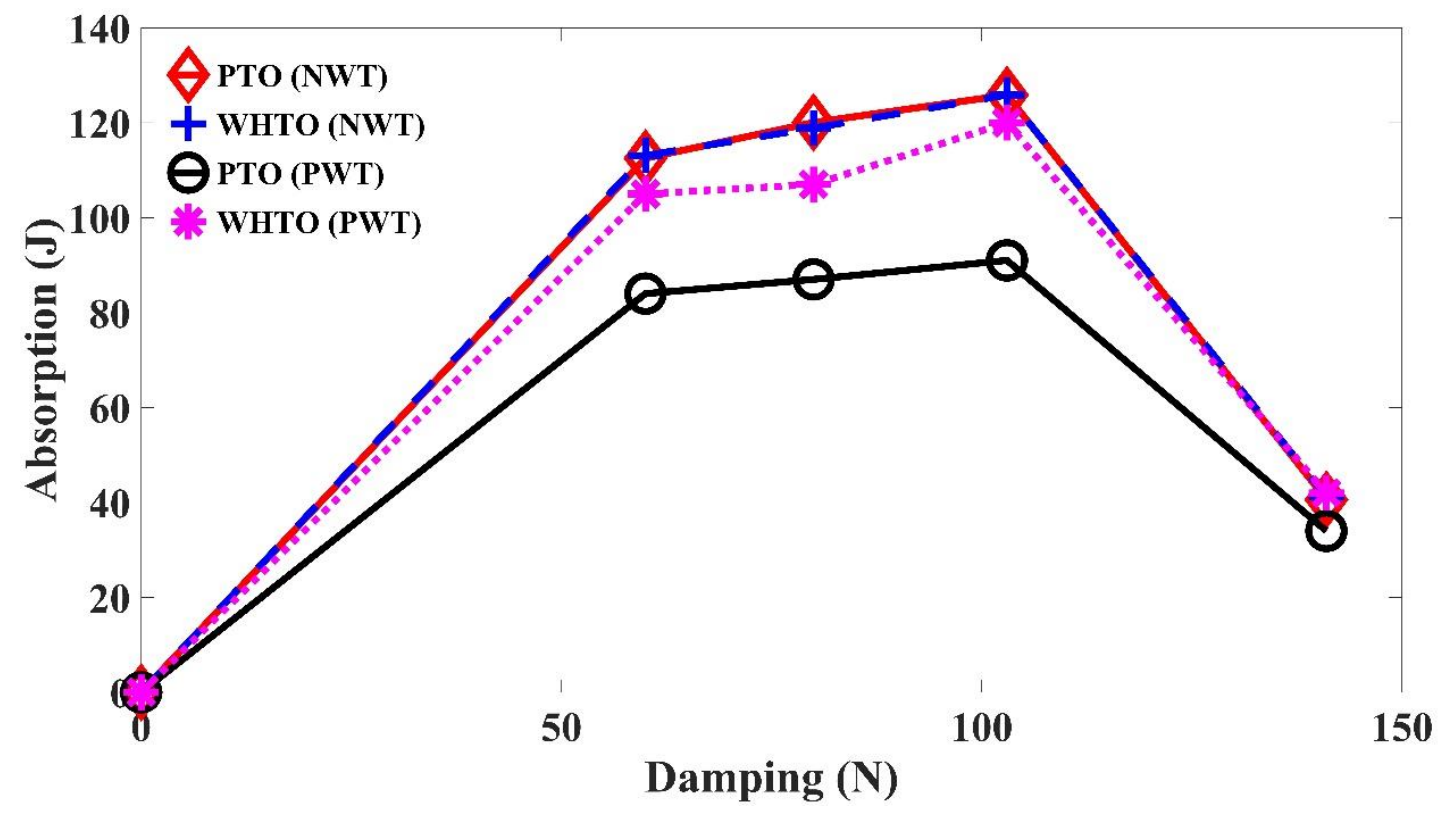

(a)

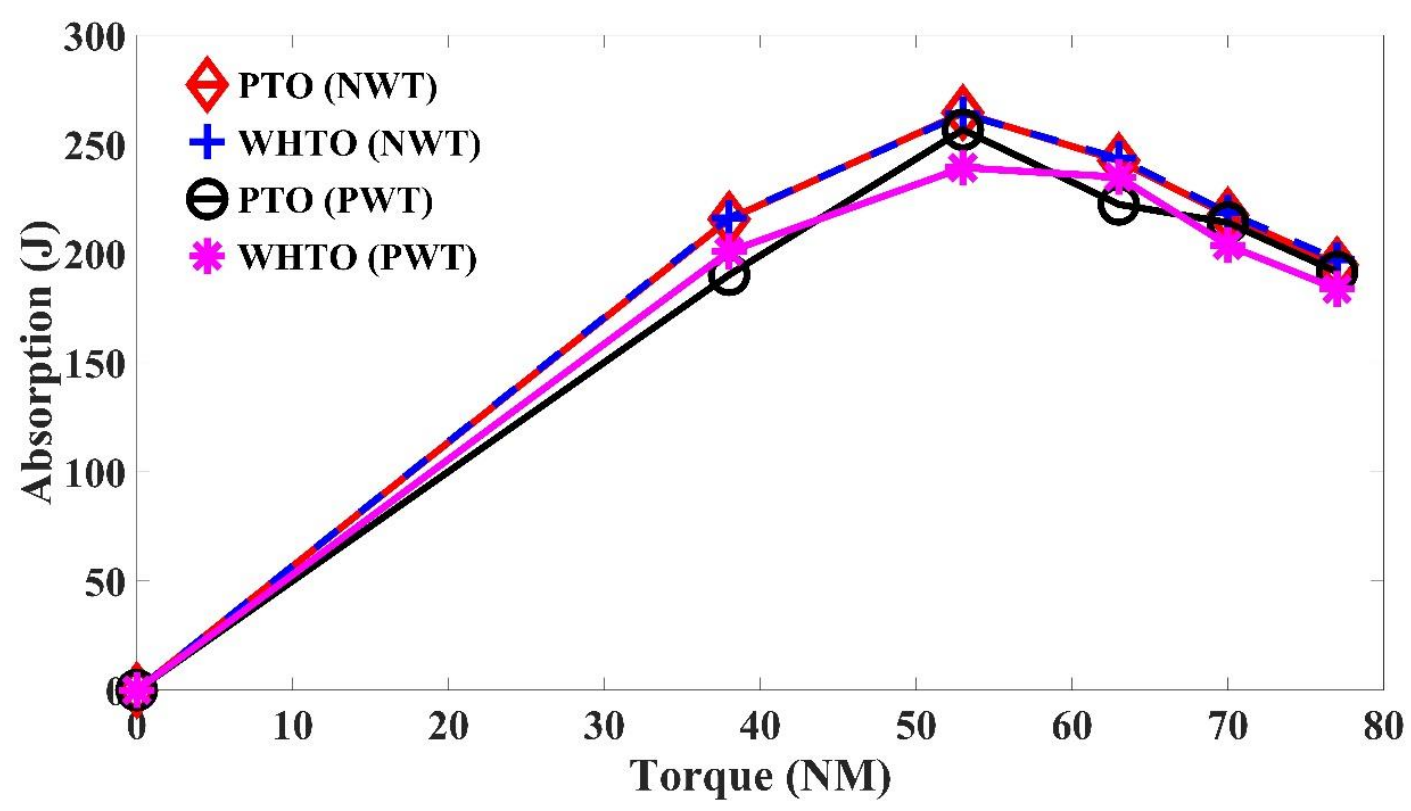

(b)

Fig.17 The difference between numerical model and physical model:(a) Heaving buoy (b). Pendulum

\section{Conclusions}

In this paper, an available method to find the energy extraction of WECs based on WHTO was proposed. A pendulum and a heaving buoy were applied to validate the method both numerically and physically. In the theoretical part, the WHTO was defined to be equivalent to the energy 
extraction by the PTO. Numerical simulation results showed that the maximum absorption was independent of damping type for both the heaving buoy and pendulum and that the difference between the absorbed energy calculated from the PTO and from WHTO was found to be insignificant.

Physical model tests of the pendulum WEC similarly showed small differences between the power calculated from the PTO and the WHTO and also gave good agreement with the numerical model simulations. Agreement was less good for the heaving buoy cases. It has been proposed that this is due to losses in the PTO system and the possible influence of wave overtopping and steeper waves breaking on the model. Comparisons with the numerical simulations suggest that PTO losses were the most significant of these three effects, demonstrating the use of WHTO as an alternative method to measure absorbed power.

For the two devices applied in the test, the pendulum had a better capture performance. Further work will attempt to validate the WHTO technique in a 3D basin to calculate the device extraction spectrum.

\section{Acknowledgments}

The author would like to acknowledge the support of the National Natural Science Foundation of China (Grant No. 41706100), the Major Program for Basic Research of Shandong Provincial Natural Science Foundation (Grant No. ZR2017ZA0202), Special Project for Marine Renewable Energy (Grant No. GHME2016YY02), the Qingdao Municipal Science \& Technology Program 158-3-7-jch and the China Scholarship Council. 


\section{References}

[1]. Guedes Soares C, Bhattacharjee J, Tello M, et al. Review and classification of wave energy converters[J]. Maritime engineering and technology, 2012: 585-594. Drew B, Plummer A R, Sahinkaya M N. A review of wave energy converter technology[J]. 2009.

[2]. Drew B, Plummer A R, Sahinkaya M N. A review of wave energy converter technology[J]. 2009.

[3]. Hossain J, Sikander S S, Hossain E. A wave-to-wire model of ocean wave energy conversion system using MATLAB/Simulink platform[C]/Development in the in Renewable Energy Technology (ICDRET), 2016 4th International Conference on the. IEEE, 2016: 1-6.

[4]. Curran R, Folley M, Danielsson O, et al. Power take-off systems[M]//Ocean Wave Energy. Springer, Berlin, Heidelberg, 2008: 189-285.

[5]. Shi H, Cao F, Liu Z, et al. Theoretical study on the power take-off estimation of heaving buoy wave energy converter[J]. Renewable energy, 2016, 86: 441-448.

[6]. Zheng S, Zhang Y, Sheng W. Maximum wave energy conversion by two interconnected floaters[J]. Journal of Energy Resources Technology, 2016, 138(3): 032004.

[7]. Sheng W, Lewis A. Power takeoff optimization for maximizing energy conversion of waveactivated bodies[J]. IEEE Journal of Oceanic Engineering, 2016, 41(3): 529-540.

[8]. Renzi E, Dias F. Resonant behaviour of an oscillating wave energy converter in a channel[J]. Journal of Fluid Mechanics, 2012, 701: 482-510.

[9]. Zhang X, Yang J. Power capture performance of an oscillating-body WEC with nonlinear snap through PTO systems in irregular waves[J]. Applied Ocean Research, 2015, 52: 261-273.

[10].Zanuttigh B, Angelelli E. Experimental investigation of floating wave energy converters for coastal protection purpose[J]. Coastal Engineering, 2013, 80: 148-159.

[11].Beels C, Troch P, De Visch K, et al. Application of the time-dependent mild-slope equations for the simulation of wake effects in the lee of a farm of Wave Dragon wave energy converters[J]. Renewable Energy, 2010, 35(8): 1644-1661. 
[12]. Nørgaard J H, Andersen T L. Investigation of wave transmission from a floating wave dragon wave energy converter[C]//The Twenty-second International Offshore and Polar Engineering Conference. International Society of Offshore and Polar Engineers, 2012.

[13]. Stratigaki V, Troch P, Vantorre M, et al. Development of a point absorber Wav Energy Converter for investigation of wake effects in large scale experiments[C]//Proceedings of the 4th International Conference on the Application of Physical Modelling to Port and Coastal Protection (Coastlab12), Ghent, Belgium. 2012.

[14].Palha, Artur, et al. "The impact of wave energy farms in the shoreline wave climate: Portuguese pilot zone case study using Pelamis energy wave devices." Renewable Energy 35.1 (2010): 6277.

[15].Stratigaki V, Troch P, Stallard T, et al. Wave Basin Experiments with Large Wave Energy Converter Arrays to Study Interactions between the Converters and Effects on Other Users in the Sea and the Coastal Area[J].

[16].Haller M C, Porter A, Lenee-Bluhm P, et al. Laboratory observations of waves in the vicinity of WEC-arrays[C]//Proceedings of the 9th European Wave and Tidal Energy Conference (EWTEC). 2011.

[17].Hirt, C. W., \& Nichols, B. (1988). Flow-3D User’s Manual. Flow Science Inc, 107.

[18].Tavella, D., \& Randall, C. (2000). Pricing Financial Instruments: The Finite Difference Method (Wiley Series in Financial Engineering). New York: Wiley.

[19].Chorin, A. J. (1968). Numerical solution of the Navier-Stokes equations. Mathematics of computation, 22(104), 745-762.

[20].Goda Y, Suzuki Y. Estimation of incident and reflected waves in random wave experiments[M]//Coastal Engineering 1976. 1977: 828-845.

[21]. Shi H, Li L, Zhao C. Optimization of wind-marine hybrid power system configuration based on genetic algorithm[J]. Journal of Ocean University of China, 2017, 16(4): 709-715.

[22].Evans DV. Power from water waves. Annual Review of Fluid Mechanics. 1981;13: 157-187.

[23].Korde U A, Ringwood J. Hydrodynamic control of wave energy devices[M]. Cambridge University Press, 2016. 